\title{
Un catecismo medieval latino-italiano
}

En la Biblioteca de la Colegiata de San Isidoro de León se conserva un manuscrito (Ms. XLVII), de cuyo autor, la única identificación posible consiste en atribuirlo a un "anónimo del siglo XV".

La descripción global que hace el Catálogo de dicha Biblioteca del manuscrito es como sigue: "Ms. en papel, 222 folios, encuadernación en tabla y cuero, y adosados al interior de las pastas dos folios en minúscula francesa del XII, que tratan de Geografía astronómica, ilustrando figuras el texto, además de la Moral en diversos tratados, tiene un compendio de catecismo, un libro de Catón, glosado en verso, "per Dmn. Catonacium militem de agnacia", himnos y demás propio de un devocionario, ciclo lunar ilustrado con profusión de figuras y tablas, etc, etc, todo en latín, y con lectura copiosa; versos profanos, un manual de parroquias, latino compuesto "per fratrem Uglesioni", que al fin se llama "libro sinodal", y por fin una historia del joven hijo de un Emperador romano, a quien su padre encomendó para su educación a siete sabios, los cuales le tenían fuera de la ciudad, y por la fama del joven llegó a enamorarse de él la Emperatriz, su madrastra, que solicitó del Emperador le mandara a vivir a Roma, para solicitarle torpemente, etc" 1 .

Sería preciso añadir a tal descripción algunos otros datos, como indicar que se trata de un volumen en $4^{\circ}$, y que las hojas no están foliadas mas que al principio por orden correlativo, en una numeración reciente, para pasar más adelante a numerar únicamente las páginas de diez en diez, lo que permite, con cierta dificultad localizar cada uno de los tratados. El libro está escrito con letra gótica del XV. Constituye una recopilación de tratados muy diversos, con la particularidad de que los varios tratados o materias no parecen guardar orden lógico alguno, pues se pasa de unos temas a otros, para volver más adelante a alguno de los que ya ha sido abordado. Además del Catecismo -que más adelante describiré con mayor detalle- el aludido "manual parroquial" incluye una exposición relativamente amplia de los sacramentos, abordados uno a uno, con vistas, evidentemente, a la práctica pastoral; asimismo incluye una explicación amplia de los pecados capitales (diversa de la que veremos en el Catecismo).

1. J. Perez Llamazares, Catálogo de los Códices y Documentos de la Real Colegiata de San Isidoro de León, León, 1923, 53. 
A pesar de que la descripción de Pérez Llamazares afirmaba estar redactado en latín, en la parte que voy a presentar aparece un tratado importante redactado en italiano. Además hay que añadir que en el conjunto del manuscrito aparecen numerosas capitales en tinta roja; pero resulta curioso observar que algunas de dichas capitales no se llegaron a escribir, por omisión del amanuense, que dejó para un segundo momento el empleo de la tinta roja, con lo cual una serie de palabras dispersas a lo largo del libro han quedado mutiladas.

Guiándome del soporte de la numeración adicional, voy a centrarme en los tratados de índole catequética que van desde el f. 141r hasta el 151v, con una interpolación (fruto del desorden general de los tratados en el manuscrito) que ocupa los f. 143r a 145r dedicada a un calendario de uso litúrgico, por lo que al total de las 22 páginas acotadas hay que restar las 5 interpoladas, con lo cual se trata en realidad de 17 páginas, y de éstas ni la primera (f. 141r) ni la última (f. 151v) completamente: todo ello da idea de la relativamente breve extensión, similar, por otro lado, a la de otros catecismos medievales.

Estos tratados de índole catequética son tres escritos perfectamente diferenciados:

1) Compendium de doctrina christiana (f. 141r-142v)

2) Orationes (f. 154v)

3) Confessio devotissima fratris Johanis de Marchia (f. 164r-151r).

Utilizaré la expresión Catecismo para designar el conjunto de los tres tratados o, en su caso, la designación peculiar de cada unos de ellos.

El orden del esquema anterior se podría modificar si se opta por considerar que son dos escritos catequéticos diversos (Compendium, y Confessio), unidos entre sí de forma meramente aleatoria por las Orationes intermedias (y, en su caso, también, por la inserción del calendario litúrgico), que no necesariamente refuerzan la precaria unidad del conjunto.

La justificación global del conjunto de los tres tratados bajo la denominación de Catecismo está sustentada por la innegable base catequética de su contenido, especialmente en el caso de los escritos primero y tercero. El Compendium de doctrina christiana, entra de lleno en el género; se parece bastante en su contenido y en su concepción a otros catecismos medievales, en los cuales también el nivel de sus explicaciones no resulta demasiado profunda por el hecho de remitir a una situación ambiental de rancio sabor cristiano que hacía poco menos que innecesarias muchas explicaciones. La Confessio tiene también un neto contenido catequético, si bien su intención directa sea la de capacitar para una adecuada confesión. Hay, además, dos datos más que deseo subrayar en esta justificación del fondo catequético de 
esta Confessio: en primer lugar, yo no sé de ningún confesional que incluya una explanación del credo, como hace éste, con la particularidad de que se limita a la presentación, pero no con miras a la confesión, inquiriendo, por ejemplo, posibles errores doctrinales en que hubiera incurrido el penitente. En segundo lugar, otros autores de catecismos, como es el caso de Pedro de Cuéllar o Hernando de Talavera escriben también sus correspondientes confesionales como complementarios de la exposición catequética de la fe, de manera que catecismo y confesional se vinculan. Tal me parece también que es el caso presente, si no en la cuestión de la autoría, sí al menos en la intención del compilador de estos tratados en el manuscrito estudiado. Por su parte, las Orationes tienen un menos nítido contenido catequético.

Personalmente me decanto por englobar los tres tratados dentro del mismo conjunto. La razón principal es la de considerar el alto contenido catequético que impregna al Compendium y a la Confessio, sin que quede interrumpido por la invitación a la oración, intercalada entre ambos. Hay, además, una unidad meramente externa, cual es la de haber sido escrito por el mismo amanuense que ha confeccionado todo el manuscrito: parece deducirse que en su mente y en su intención también estaba esta concepción unitaria, puesto que sólo rompe la continuidad estricta al final del f. 145r con un escueto "deo gratias", que señala inequívocamente el final del calendario litúrgico interpolado ${ }^{2}$, de la misma manera que al término de la Confessio (f. 151v) aparece de nuevo, semirrecuadrada, la leyenda "deo gratias", con la que pone fin al tratadito. Son, pues; tres tratados diversos, intencionalmente vinculados entre sí en la idea del compilador, como escritos que se complementan unos a otros.

\section{AUTOR}

No existe en el conjunto del manuscrito identificación alguna que permita localizar a un autor de la totalidad, pues la descripción anterior permite la localización de varios autores particulares referidos a ciertos tratados, pero no a la obra completa, por lo cual, en la reseña anterior figura como anónimo.

2. Con anterioridad a este final, en el transcurso del calendario litúrgico, ha dibujado un recuadro en cuyo interior se lee "hec vero", al final del f. $143 \mathrm{v}$, que parece ser un error pues no empalma ni con el texto anterior, ni con el que le sigue. La impresión de error se refuerza por el hecho de que en el f. 144v aparece recuadrada al final de la página, a título de reclamo (el libro carece de ellos) la indicación "hec vero inferius", pues el f. 145r comienza su texto precisamente: "hec vero inferius scripta sunt illa de quibus incipitur capitulo primis vesperis...". 
Concretamente, el Compendium de doctrina christiana carece de toda consignación de autor, y su texto tiene las suficientes semejanzas y diferencias con otros catecismos medievales como para no permitir la atribución a alguno de los autores conocidos. Algunos rasgos internos (como en el caso de los Mandamientos de la Iglesia y de los Sacramentos) permiten sospechar que el autor no es español, pues no se ajusta ni a la formulación ni a las afirmaciones complementarias que solían acompañar estos dos formularios en los catecismos españoles, pero tal razón no resulta determinante.

Las Orationes, que constituyen la segunda parte, tienen un inequívoco sabor italianizante, sabor que viene reforzado por el hecho de que en la anotación que acompaña a las indulgencias remite expresamente a Roma: "ut patet in urbe rome clarius in conventu", aunque lamentablemente no haya datos para permitir identificar de qué convento romano se trata. Todo ello se corrobora con mayor verosimilitud por el hecho de que la Confessio devotissima aparezca asignada a "fratris johanis de marchia".

A falta de mejores indicios para el conjunto de la composición catequética, la Confessio posibilita al menos la localización del autor de uno de los escritos, con absoluta seguridad; permite suponer que no sería aventurado atribuirle la composición de las Orationes de la segunda parte, y deja en libertad para asignar la autoría del Compendium a otro posible autor, puesto que la unidad catequética a que antes me refería es la que se deduce de la mentalidad del copista, pero no necesariamente hay que identificarla con la unidad de autor.

Juan de la Marca, llamado en realidad Juan de Ripa, pues era natural de Ripatransone, cerca de Ascoli Piceno, en La Marca, llevó igualmente el sobrenombre de su región de origen. Ambos apelativos hacen referencia a su origen, si bien se puede asegurar que su apellido familiar era el de Plantadossi ${ }^{3}$. Se desconocen de él datos precisos como las fechas de nacimiento o muerte, llegada a París, acceso concreto a la enseñanza. Perteneció a la orden de los franciscanos, en la que destacó como teólogo y filósofo, ya que ejerció con éxito el magisterio en la universidad de París durante el tercer cuarto del siglo XIV ${ }^{4}$. Según el cronista Mariano de Florencia, enseñaba antes de los 30 años y fue conocido con el apelativo de Doctor difficilis. En opinión de Wadding, Juan de Ripa se habría ocupado de la cuestión del cisma griego, ya que después de 1370 se pierde todo vestigio de él en París,

3. A. Combes, Jean de Ripa. Lectura super Primum Sententiarum. Prologi. Quaestiones I et II (Edition critique), Paris, Librairie Philosophique J.Vrin, 1961, XVII.

4. A. COMBES, Présentation de Jean de Ripa, en "Archives d'histoire doctrinale et litteraire du Moyen Âge" 23(1957) 157-159 analiza las razones por las cuales una datación entre los años 1316-1334 para su docencia ha de ser desplazada a los años 1345-1370. 
para reaparecer hacia 1400-1402 citado en los escritos de Gersón, lo que lleva a suponer que para entonces ya había muerto5.

A. Combes cita como obras suyas: 1) Lectura super Libros Sententiarum $^{6}$, 2) Collatio de gradu supremo, 3) Determinationes ${ }^{7}$, 4) Disputatio de causa meriti ${ }^{8}$. Otras obras no encontradas: 5) De formalitatibus, 6) In aliquot Aristotelis libros de anima, 7) De virtutibus, 8) De vitis, 9) Sermones de tempore, 10) Sermones de Sanctis, 11) Tractatus de contractibus 9 . En la bibliografía estudiada por A. Combes, no aparece referencia alguna a esta Confessio, que sin embargo, el manuscrito estudiado le atribuye sin el más mínimo vestigio de duda. Esta obra estaría situada no tanto en la línea de reflexión teológica, propia de su docencia universitaria, sino en la de los Sermones de tempore y los Sermones de sanctis

\section{FECHA}

Los indicios que permitan señalar una fecha de composición de esta obra son muy escasos, pues la única referencia segura apunta a Juan de la Marca, cuyo apogeo se sitúa en el tercer cuarto del siglo XVI, pero del que se desconoce la fecha de fallecimiento, por lo cual, esta tercera parte tendría que ajustarse a tan imprecisa datación. En el caso de las dos partes anteriores no hay datos más concretos, pues el único indicio cronológico es la alu-

5. Han tratado de Juan de Ripa: F. Ehrele, Der Sentenzkommentar Peters von Candia des Pisaner Papstes Alexander V, Münster in Westfalia, 1925; H. SchwaMm, Magistri Ioannis de Ripa, O.F.M. doctrina de prescientia divina. Inquisitio historica, Roma, Analecta Gregoriana, 1930; Id., Das göttliche Vorherwissen bei Duns Scotus und seinem ersten Anhängern, en Philosophie und Granzwissenschaften, V. Band 1/4 Heft, Innsbruck, 1934; A. CoMBES, Un inedite de Saint Anselme? Le traité "De unitate divinae essentiae et pluralitate creaturarum" d'aprés Jean de Ripa, Paris, 1944; Id., Présentatio de Jean de Ripa, en "Archives d'histoire doctrinale el litteraire du Moyen Age" 23 (1957) 145-242; Id., Les réferences de Jean de Ripa aux livres perdus (II,III, IV) de son commentaire des Sentences, en Ibid.(1959); F. RuELLO, Paulus Venetus. Super Primum Sentantiarum Johannis de Ripa lecturae abbreviatio. Prologus, (Edition Critique), Firenze, Olschki, 1980); L. WADDING, Scriptores ordinis minorum, Romae, 1650.

6. A. Combes, Lectura super Primum Sententiarum.Prologi. Quaestiones I et II. (Edition critique). Paris, J. Vrin, 1961. A. Combes, Conclusiones, (Ed. critique), Paris, J. Vrin, 1957 presenta en esta obra las conclusiones que van marcando los hitos del pensamiento de Juan de Ripa en el transcurso de su comentario a las Sententias de Pedro Lombardo.

7. A. Combes, Determinationes, (Ed. crítica), Paris J. Vrin, 1957. Esta obra se conoce también con el nombre de Quodlibeta.

8. A. Combes, Présentation de Jean de Ripa, 1.c., 170-176.

9. Ver A. COMBES, Jean de Ripa ou de Marchia, en G. JACQUEMET (ed.), Catholicisme, hier, aujordiu, demain, tomo VI, 561-563. 
sión a las indulgencias concedidas "a beato gregorio et multis aliis eius susscessoribus", que no permite más concreciones ${ }^{10}$.

Respecto a la fecha de la escritura del manuscrito, ya he indicado que está catalogado como del siglo XV, extremo suficientemente comprobado como para no ofrecer dudas. Además del tipo de letra gótica, el latín empleado es un latín bajomedieval, decadente, inseguro; y, por otra parte, el italiano: que aparece en la Confessio es también un italiano poco afianzado, con evidentes dependencias del latín (lo que es equivalente a arcaísmo) y, acaso también del castellano.

Hay que hacer una precisión más en el sentido de que resulta patente que el manuscrito que hoy nos ha llegado es copia de un escrito anterior, ya que en varias ocasiones el amanuense se equivoca repitiendo una palabra por dos veces en la misma frase que posteriormente tacha ${ }^{11}$, mientras que en otras ocasiones se despista dejándola sin $\operatorname{tachar}^{12}$, además de tener que añadir una línea forzada que ha omitido, alterando el sentido de la lectura ${ }^{13}$. Pero tal constatación no permite ir más lejos en la averiguación de la fecha de los escritos copiados en el presente manuscrito durante el siglo XV.

\section{APROXIMACION A UN ANALISIS LINGÜISTICO}

No voy a tratar de llevar a cabo en este apartado un estudio sistemático desde el punto de vista lingüístico, sino únicamente una aproximación para señalar algunas peculiaridades del idioma empleado. La fecha del siglo XV, aun resultando poco concreta, es lo suficientemente nítida como para saber que estamos asistiendo a la agonía del uso habitual del latín, que va cediendo paso a los cada vez más potentes idiomas románicos. Es un período de transición, y asistimos a la decadencia de un latín alejado de sus fuentes clásicas y muy romanceado; y por otro lado las nuevas lenguas todavía no han adquirido la autonomía que irán cobrando con el paso del tiempo. De ahí que los dos idiomas que aparecen en este Catecismo compartan la ambigua situación de transición hacia la desaparición o hacia la consolidación.

10. Si "beato gregorio" hay que entenderlo como "San Gregorio", tampoco una alusión tan génerica permite mayores concreciones, pues podría referirse a San Gregorio Magno (Gregorio I), cuyo pontificado fue del 590 al 604, a San Gregorio II (715-731), o a San Gregorio III (731-741), por no mencionar a los otros Gregorios, no beatificados, hasta Gregorio XII (1406-1415), a cada uno de los cuales se podría atribuir la concesión de indulgencias, pues son anteriores a la fecha supuesta la de escritura del manuscrito.

11. Líneas 166,189 y $238-239$.

12. Líneas 11 y 113.

13. Líneas 363-364. 
Salvando la cuestión de las abreviaturas, desatadas con arreglo al sentido del texto latino según la grafía usual, en el resto del escrito no sometido a abreviaturas me voy a ceñir a señalar algunas muestras del latín utilizado, dejando constancia de que se trata de un latín decadente.

En el Compendium aparecen expresiones usuales en el latín tardomedieval, como celi (por coeli, línea 5), Pillato (por Pilato, línea 8$)^{14}$, tercia (por tertia, línea 9), hec (por haec, línea 15), misericordie (por misericordiae, línea 22), sicientes (por sitientes, línea 28), posquam (por postquam, línea 39), Bautisma (por Baptisma, línea 50) ${ }^{15}$, cautivos (por captivos, línea 28$)^{16}$. Todas ellas son muestras de corruptelas fonéticas o gráficas en un idioma que aunque resulta sabido no es correctamente utilizado. Otro tanto ocurre con las Orationes, donde se encuentran las expresiones siguientes: anime mee (por animae meae, línea 95), susscesoribus (por succesoribus, línea 101), eclesie (por ecclesiae, línea 105).

La Confessio, redactada en italiano, es igualmente patente demostración de un empleo irregular de una buena serie de palabras. Encontramos con una clara reminiscencia latina: septima (por settima, línea 123), regula (por regola, línea 112), scriptura (por sćrittura, línea 209), aut (por "o", conjunción adversativa, línea 239), supraditte (por sopraditte, línea 128), constientia (por coscienza, línea 127). Otras muestras van en la línea de indicar la inseguridad o el arcaísmo del italiano utilizado, como es el caso de usar vechia (por vecchia, línea 187), paçci (por pazzi, línea 372), magnare (por mangiare, línea 219). En otros casos resulta más evidente la castellanización que han sufrido algunas de las palabras empleadas como en el caso de cuerpo (por corpo, línea 352), mundo (por mondo, línea 179), o qualquier (por qualcunque, línea 238).

Además encontramos otros vestigios de inseguridad a la hora de utilizar una $u$ otra palabra, que muestran la vacilación del autor. Tal es el caso del empleo de ecclesia (línea 251) o chesia (por chiesa, línea 236); similar situación es la que aparece en el uso del latinismo infanti (línea 274) o bien lavoratori (línea 193) para hacer alusión a los trabajadores; otro tanto ocurre con la variante limosine (línea 196) o su precedente latino elimosine (línea 373). Ya hice alusión con anterioridad al empleo en el texto italiano de la misma corruptela que había utilizado en el texto latino al escribir Pillato (línea 349).

14. La misma irregularidad́ aparece en el texto italiano de la Confessio (línea 324), lo que resulta indicativo de la inseguridad del autor tanto en uno como en otro idioma.

15. En este caso es clara la castellanización, pues no se inclina por la fórmula italiana Battesimo, ni por otra forma del latín decadente fonéticamente afin, como Babtisma. Curiosamente, también en el texto italiano aparece la expresión "bautismo" (línea 338).

16. Como en el caso anterior, es un nuevo indicio de castellanización. 
En otros casos la inseguridad se manifiesta en el uso alternativo de dos grafías diferentes, en que una vocal se substituye por otra que fonéticamente suena igual o casi igual, lo que induce a que gráficamente se intercambien una y otra; así encontramos iudei (línea 223) o iudey (línea 230); altrui (línea 150) o altruy (línea 141); sei (línea 137) o sey (línea 134); ai (línea 329) o ay (línea 329); bueni (línea 144) o buono (línea 126).

El conjunto de tales muestras manifiestan el empleo habitual en esa época de un latín decadente y mal utilizado y de un italiano inseguro y vacilante: es un texto de la época de transición en que un idioma se va abriendo paso a costa del otro y en que ninguno de los dos tiene suficiente firmeza como para imponerse de una forma nítida. Por otro lado, el hecho palpable de la castellanización de algunos de los vocablos utilizados puede reflejar la intervención de alguna persona (¿amanuense?) que quizá con otro esquema mental no está absolutamente seguro de las expresiones que utiliza por un cierto desconocimiento, lo que llevaría a la hipótesis de algún personaje que piensa en castellano y escribe en italiano: en este caso, a pesar de los despistes, demuestra un excelente conocimiento del italiano, y sólo cuando baja la guardia se descubre su personalidad a través de los inconscientes errores. De todas maneras los indicios de castellanización no son tantos como para llevar esta hipótesis a tesis, aunque convenga no relegarlos totalmente al olvido.

\section{ANALISIS CATEQUETICO Y DOCTRINAL}

Puesto que se trata en conjunto de un catecismo, no queda otro remedio que hacer un análisis a fondo desde los supuestos catequético y doctrinal que el catecismo contempla, como son la forma de presentar la fe y el fondo mismo en que ésta es comunicada, conscientes de que fondo y forma están íntimamente vinculados entre sí y no siempre resulta fácil la separación metodológica.

En aquellas ocasiones en que resulte procedente, voy a tratar de comparar este Catecismo con otros catecismos medievales, para ver de establecer las semejanzas y diferencias, aunque no hay más remedio que advertir que la escasez de ejemplares, referidos a un tiempo extremadamente amplio hace difícil establecer adecuadamente los términos de la comparación. La única nota que salva la validez de la comparación es la tendencia a la estabilidad propia de la sociedad medieval inclinada al empleo de fórmulas estereotipadas que continuaban siendo válidas generación tras generación lo que en cierto modo resta importancia a la distancia temporal entre los catecismos que voy a comparar. 
Estos catecismos son: el de Pedro de Cuéllar (=PC), de $1325^{17}$, el de Juan de Aragón (=JA), de 1328-1334, el de Gil de Albornoz (=GA), de 1345$1347)^{18}$, el de Gutierre de Toledo (=GT), de 1377-1385 ${ }^{19}$, un catecismo anónimo hispano-latino $(=\mathrm{HL})$, de los siglos XIV-XV²0, otro catecismo anónimo que empieza con las palabras "La santa fe de los christianos..." $=(\mathrm{SF})$, de 1469(? $)^{21}$, el catecismo de Hernando de Talavera (=HT), de hacia $1496^{22}$.

Seguiré el mismo orden que el Catecismo que estoy presentando con la salvedad de introducir divisiones y numeración que no están en el texto original para facilitar el orden lógico.

\section{COMPENDIUM DE DOCTRINA CHRISTIANA}

\section{Padre nuestro.}

El texto comienza, tras el título medio camuflado en el semirrenglón del párrafo anterior ("Incipit Compendium de doctrina christiana"), con la afirmación de que "quilibet christianus debet primo scire pater noster ut possit orare". Resulta curiosa la incóngruencia en que el Catecismo incurre, pues frente a la urgencia destacada en primer lugar no se sigue el texto del padrenuestro. Es más que posible que no fuera necesario ponerlo por escrito si resultaba suficientemente conocido y repetido en la práctica cristiana del momento, pero no deja de llamar la atención que si estima fundamental su conocimiento no dedique un párrafo a transcribirlo, precisamente para asegurar y reforzar su conocimiento. La misma ausencia se percibe en los catecismos consultados, con la única excepción de que HT (f. 11r) lo incluye entre sus páginas en versión castellana.

17. Edición a cargo de J.L. MARTin-A. Linage, Religión y sociedad medieval. El Catecismo de Pedro de Cuéllar (1325), Salamanca, Junta de Castilla y León, 1987.

18. Ambos publicados por D. W. LOMAX, El catecismo de Albornoz, en E. VERDERA Y TuEllas (ed.), El Cardenal Albornoz y el Colegio de España, Bolonia, 1972, I, 213-233.

19. A.C. Floriano, Un catecismo castellano del siglo XIV, en "Revista Española de Pedagogía" 3 (1945) 87-99. 126.

20. J. Homs, Un catecismo hispano-latino medieval, en "Hispania Sacra" 1 (1948) 113-

21. J. SANChez HERRERo, La enseñanza de la doctrina cristiana en algunas diócesis de León y Castilla durante los siglos XIV y XV, en "Archivos Leoneses" 59-60 (1967) 167-169.

22. Breue doctrina y enseñança que ha de saber y poner en obra todo christiano y cristiana. En la qual deuen ser enseñados los moçuelos primero que en otra cosa. Ordeno la Fray Hernando de Talauera: primero arçobispo de la santa yglesia de Granada. 
No hay más remedio que hacer alusión a otro documento medieval, según el cual, habiendo encontrado Carlomagno a algunos que querían ejercer el cargo de padrinos sin saber ni el credo ni el padrenuestro, fueron excluidos de tal oficio ${ }^{23}$, lo que confirma la urgencia de la afirmación inicial del Catecismo, a pesar de que no sea vea complementado con el texto del mismo.

\section{Credo.}

A diferencia de los otros catecismos consultados, el presente opta en la presentación de la fe por la fórmula del credo apostólico, en la modalidad (certificada por otros muchos catecismos más recientes) de atribuir cada uno de los artículos a uno de los apóstoles, como expresamente advierte: “...quae in eodem continentur XII articuli fidei secundum numerum XIIm apostolorum". Como tal atribución no tiene fundamento histórico real y la tradición que la repite es meramente supuesta, de ahí que haya variantes en la misma, como es el caso del Catecismo que nos ocupa, pues atribuye a Mateo la frase: "Sanctam eclesiam catholicam", y a Simón dos frases: "Sanctorum communionem, remissionem peccatorum". Tal atribución no se muestra concorde con la que hace el catecismo de Pedro de Cuéllar, para el cual Mateo es el autor de "Sanctam ecclesiam, sanctorum communionem", dejando a Simón la frase restante (PC, $2 v)$. Hay otra diferencia igualmente con el catecismo de Pedro de Cuéllar, cual es la mayor fidelidad del texto del catecismo presente, pues atribuye a Andrés la frase: "Et in ihesum christum filium eius unicum dominum nostrum"(línea 5-6), en tanto que el catecismo de Pedro de Cuéllar modifica la frase para afirmar, también en labios de Andrés: "Et in ihesum christum filium eius unicum Domini"24.

23. "Multi fuerunt apud nos inventi qui volebant suscipere infantes, de sacro fonte batismatis, quos iussimus singulariter et diligenter examinare et requirere, si orationem Dominicam et symbolum scirent, et memoriter tenerent; el plures fuerunt qui nulla exinde in memoriam tenebant, quibus praecepimus abstinere et antequam orationem et symbolum scirent et recitare potuissent, neque aliquem de sacro fonte baptismatis suscipere praesumerent" Ep. XV ad Garibaldum (PL, XCVIII, 917). Citado por D. LloRENTE, Tratado elemental de Pedagogía Catequística, Valladolid, Martín 19945513.

Por su parte el catecismo de Pedro de Cuéllar (PC 19v) sí recoge la necesidad de que el cristiano conozca las oraciones, pero lo hace en otro contexto: se dirige expresamente al sacerdote para que cumpla con su quehacer catequético por la enseñanza, a la vez que para que controle a través del ministerio de la penitencia quiénes lo saben y quiénes lo ignoran, con esta advertencia: "Primero le demande dónde es e dó fue criado; e si le viere simple demuéstrele el Pater noster e el Ave Maria e el Credo o amonéstele que lo aprenda".

24. Ver J.N.D. Kelly, Primitivos credos cristianos, Salamanca, Secretariado Trinitario, 19803, 469-509. 
La otra curiosidad, ya anotada al hacer el análisis lingüístico es la inusitada grafía "Pillato", que aparece tanto en el texto latino como en el italiano (líneas 8 y 339), de la cual no he encontrado paralelo en ningún otro sitio.

El catecismo de Hernando de Talavera presenta la fe en torno al credo apostólico en castellano, sin atribución a cada uno de los apóstoles de la frase correspondiente (HT, 10v); los catecismos de Pedro de Cuéllar (PC, 2rv) y de Juan de Aragón (JA, 270v,b-271r,a) incluyen la fe según la ordenación de los catorce artículos de la fe, pero además, a título de resumen, ofrecen la formulación en doce artículos del credo apostólico, aunque el segundo no distribuya los artículos según los apóstoles. El resto de los catecismos consultados los presenta según el esquema usual en los catecismos españoles de los catorce artículos de la fe, sin que tenga que deducirse que el ajustarse al credo apostólico, como hemos visto, sea indicio seguro de procedencia extranjera.

\section{Mandamientos.}

"Post hec discat precepta". La primera y más chocante nota que procede resaltar es que enumera únicamente nueve mandamientos, aunque en la recapitulación que les sigue, en forma de versos, haga referencia a diez. Es suficientemente conocido que la distribución catequética cristiana ${ }^{25}$ no se ajusta literalmente a la expresión veterotestamentaria, que sistematiza y abrevia. En el caso que nos ocupa más que la fusión de los dos últimos preceptos en la frase "Non concupisces res proximi tui", llama más la atención la enunciación del primer mandamiento por la vía negativa "Non adorabis deos alienos", que por la vía positiva: "Diliges Dominum Deum tuum". La redacción propuesta por el Catecismo es prácticamente la misma que la de la Vulgata $^{26}$. Otra anomalía digna de ser reseñada es que altera el orden de los mandamientos sexto y séptimo: “...Non occides. Non furtum facies. Non

25. Forzosamente hay que matizar que la palabra "cristiana" es usada aquí en su sentido más amplio, englobando a los seguidores de Cristo. Con posterioridad a la reforma, habría que matizar y decir "católica", que siguió usando los esquemas habituales, en tanto que los reformadores de uno y otro signo, en una mayor fidelidad a la literalidad del texto siguieron usando el esquema del decálogo recuperando como $2^{\circ}$ mandamiento la prohibición de hacer imágenes, y fundiendo en el $10^{\circ}$ la apetencia de propiedades y de la mujer ajena. La tradición ortodoxa coincide en este punto con la tradición protestante y difiere de la católica: ver, Dio è vivo (Catechismo per tutti scrito da un gruppo di cristiani ortodossi), Leumann-Torino, LDC, 1989, 106.

26. Solamente hay divergencias en: $1^{\circ}$ mandamiento:" Non habebis deos alienos..." (Vulgata); "non adorabis deos alienos; $8^{\circ}$ mandamiento: "Non loqueris contra proximum tuum falsum testimonium" (Vulgata); "non falsum testimonium dices"; $9^{\circ}$ mandamiento: "Non concupisces domum proximi tui" (Vulgata); "non concupisces res proximi tui". 
mechaberis...", sin que aparentemente haya razón alguna que justifique semejante cambio.

Esto no afecta para nada a dicha presentación que, como puede apreciarse es meramente esquemática frente a otros catecismos con los que se puede establecer comparación, que optan por la línea de una presentación realmente amplia, o una más condensada, señalando junto al enunciado de cada uno de los mandamientos los posibles pecados más notables o más usuales contra el mismo; tan sólo optan por la presentación escueta el catecismo hispano-latino (HL, 293v-294r) y el anónimo leónes (SF, 297r).

A título de resumen mnemónico de los mandamientos, incluso en su formulación condensada, algunos catecismos incluyen unos versos, que solían ser un procedimiento práctico en el medievo, habida cuenta de los índices de analfabetismo. Incluyen asimismo versos de esta índole GA, 103r; JA, 273r,a; y HL, 293v. Pero en el estudio de J. Homs previo al catecismo hispano-latino, menciona en nota un manuscrito de Brujas $^{27}$ que es el que más coincide con los versos del Catecismo que estoy analizando, además de coincidir, también en parte, con la redacción del catecismo hispano-latino. Por otra parte, los versos del manuscrito de Brujas quedan mutilados al final, mientras que los del este texto no tienen mutilación alguna.

\section{CATECISMO DE SAN IsIDORo}

Unum cole deum, nec iures vana per ipsum Sabata santifices. Habeas in honorem parentes Non sis occisor, fur,...ctus, testis iniquus Uxorem alterius. Nec cupias res alienas.

\section{MANUSCRITO DE BRUJAS}

\section{In tabulis binis, lex erat scripta petrinis} Unum crede Deum, ne iures vana per Ipsum. Sabbata sanctifices, et sint in honore parentes. Non occisor eris, mechus, fur, testis iniquus.

A pesar del parecido de los versos, no se puede aquilatar la absoluta identidad en ninguna de las versiones, lo que constituye una prueba de que circulaban una serie de estrofas parecidas, pero no iguales, y nuestro Catecismo se hace eco de una de tantas, con las semejanzas y divergencias que se pueden apreciar.

\section{Mandamiento evangélico.}

El texto prosigue con una frase de la cual he hecho un apartado más, no precisamente por su extensión, sino por la importancia que tiene en sí

27. Pg. 119. Ver pg. 115 en que señala que dicho manuscrito de Brujas fué publicado por A. de POORTER, en "Revue d'Histoire Ecclésiastique" 28 (1932) 70-74. 
misma: el hecho de que la presentación de los preceptos, con una versión que es copia casi literal de las palabras del Exodo, se remate haciendo alusión a "Precepta evangelii sunt duo", no deja de ser un acierto catequético. Ahora bien, semejante logro queda inmediatamente desvanecido, ya que contra todos los pronósticos, no continúa con la formulación de los dos preceptos evangélicos a los que está aludiendo, sino que deriva hacia la puesta en práctica de los mismos, a través de las obras de misericordia.

Encontramos en otros catecismos parecidas alusiones a la ley evangélica, aunque no resulten coincidentes entre sí. HT, 16v dice: "Hazer a los otros el bien que querriamos que hiziessen a nos, y no les hazer el mal que no querriamos que nos hiziessen", con una clara referencia a Mt. 7,12. Por su parte, JA 270v, a parece que trata de coincidir con nuestro Catecismo al decir: "Lex autem Christi in duobus consistit, in fide, scilicet, et moribus"28. El hecho de que el presente Catecismo no prosiga la frase impide saber si en el resumen evangélico -que el autor únicamente apunta- está pensando como HT en hacer el bien y evitar el mal; como JA, en la fe y las obras; o en Mt. 22, 34-40, en el amor a Dios y al prójimo.

\section{Obras de misericordia.}

Como ya he indicado, la fugaz contemplación del mandamiento evangélico modifica su trayectoria, y en lugar de ahondar en la moral neotestamentaria y en la enseñanza de Jesús según las expresiones bíblicas, aterriza en la formulación usual de las obras de misericordia: "Precepta evangelii sunt duo qui distingunt in opera misericordie". La enumeración de las mismas se articula, según la doble división conocida, en obras de misericordia espirituales y corporales. Hablando en términos globales se puede decir que se ajustan a los patrones comunes en este tipo de prácticas cristianas, teniendo en cuenta que no existe un modelo suficientemente fijado como para que se convierta en arquetipo, lo cual conlleva ciertas fluctuaciones de la redacción o en el orden en que aparecen.

En nuestro texto aparecen primero las espirituales, seguidas de las corporales, mientras que en el catecismo hispano-latino, figuran en orden inver-

28. GA, 102r propone otro compendio de los mandamientos, que tiene una tradición fuertemente catequética, si bien no resulta tan evangélico: "Otrosí deuemos saber que los mandamientos de la ley de Dios son diez, e destos diez mandamientos los tres de la primera tabla pertenesçen al amor de Dios, e los otros siete pertenesçen al amor que deue auer todo omne a su Christiano". Casi en términos parecidos se expresa JA, 272v,a: "Quorum tria pertinent ad dilectionem Dei et hec fuerunt scripta in prima tabula, VII alia ad dilectionem proximi pertinent que scripta fuerunt in secunda tabula". El mismo JA, 273r, a dice: "in his mandatis universa lex pendet et prophete" (Mt. 22,40). 
so (HL 295v-296v) ${ }^{29}$. Las obras de misericordia espirituales aparecen en lo que podríamos llamar formulación tradicional, con una serie de particularidades.

Llama la atención la expresión que emplea para la 6a: "Substinere personas graves", cuyo sentido podría resultar de alguna manera ambiguo o confuso. El cotejo con otra formulación medieval nos precisa el alcance de la afirmación, cuando en otro catecismo se afirma: "La sesta es sonfrir al enojoso e al enfermo e al sannudo" (GT pg. 99). Respecto a la $7^{\text {a }}$, nuestro Catecismo dice: "orare por omnibus, scilicet, amicis et inimicis", con lo que aporta un rasgo de originalidad en tal plegaria universal que no he encontrado reflejado en ningún otro catecismo de esta época; tan sólo se le aproxima algo la siguiente: "La septima es rogar a Dios porque todos los omnes ayan bien..." (GT pg. 99) ${ }^{30}$, aunque no incluye expresamente el matiz de recordar en la oración tanto a los amigos como a los enemigos. Al término de las obras de misericordia, éste y otros catecismos hacen un resumen en forma de verso latino, pero en el caso del presente Catecismo comete la irregularidad de condensar en seis verbos las siete obras de misericordia: "Unde versus: Consule, castiga, solare, remitte, fer, ora". Se trata, evidentemente, de una omisión del despistado amanuense que por fortuna se puede obviar al contraste con el único catecismo que reproduce en latín tal verso: "Consule, castiga, solare, remite, fer, ora, doce" (HL 296r) ${ }^{31}$.

Respecto a las obras de misericordia corporales, las siete que incluye la formulación del presente Catecismo se ajustan a la formulación habitual, aunque no haya un orden inalterado; y terminan en el verso conclusivo que en este caso sí está integrado por siete miembros: "Unde versus: Visito, poto, cibo, reddimo, tego, colligo, condo". Puede comprobarse, por comparación con las espirituales en las que no había variación, cómo han cambiado los verbos empleados, así como el orden: "Pasco, poto, coligo, tego, visito, libero, condo"32.

29. En el caso de HT 16v, aborda las obras de misericordia de una forma global, breve, sin llegar siquiera a enumerarlas más que para destacar -sin que se adivine el motivo últimouna de ellas: "Cumplir las obras de misericordia que son socorrer a las personas en sus menesteres spirituales e corporales. E señaladamente corregir aparte caritativamente al que yerra".

30. El catecismo de Gil de Albornoz (GA 103v) contiene unas expresiones casi iguales a las reproducidas del texto de Gutierre de Toledo.

31. SF 297v únicamente esquematiza las obras espirituales en la forma del verso aludido, pero traducido al castellano: "Enseñar, aconsejar, castigar, consolar, sofrir, perdonar, rogar". El resto de los catecismos consultados, o no incluye las obras de misericordia, o no recoge el verso recapitulativo.

32. GT pg. 99; GA 103v; SF 297v aporta el verso, como en el caso anterior, en su versión castellana: "visitar, dar de comer, dar de bever, redemir, vestir, dar posada, enterrar". 


\section{Mandamientos de la Iglesia.}

Este tratado resulta absolutamente original, en la presentación que del mismo realiza este Catecismo. Por otra parte, frente a las fórmulas escuetas y estereotipadas de otros formularios (como es el caso de las obras de misericordia), en el caso de los mandamientos de la Iglesia, el texto se encuentra lleno de matices y precisiones como si existiera una preocupación de dejar suficientemente explicitados tales preceptos. Choca tal interés cuando ha habido ocasión de comprobar que no ha incluido algo semejante unas líneas más arriba al recoger los mandamientos de Dios.

El segundo motivo de originalidad se encuentra en el hecho de que es prácticamente el único catecismo que aborda la cuestión, ya que la mayoría de los consultados no lo hace, y el único que recoge alguno de estos mandatos -el de Hernando de Talavera- lo hace de una forma no sistemática, de manera que no puede decirse que lo excluya, pero tampoco lo presenta como un capítulo fácilmente memorizable de deberes a cumplir ${ }^{33}$.

Todos los mandamientos comienzan su redacción con la fórmula: Quilibet christianus...", que ya había aparecido (línea 2 ) al hablar de la obligación de conocer el padrenuestro: denota una obligación expresa. El $1^{\circ}$ mandamiento recuerda de nuevo la obligación de saber precisamente estos dos formularios ("pater noster et credo in deum"); y añade, además la obligación que tienen los padrinos ("patres et matres spirituales") de enseñar a sus ahijados ("filios suos spirituales") al llegar a la edad oportuna, que no precisa ("ad hetatem legitimam"). Resulta curioso que no se haga siquiera una alusión a la labor educativa de los padres, y que todo el peso de la enseñanza cristiana recaiga sobre los hombros de los padrinos. Recuérdese lo anotado en cuanto a la actuación de Carlomagno en este punto ${ }^{34}$.

El $2^{\circ}$ mandamiento contempla el descanso dominical con la abstención de trabajos serviles, de las cosas ilícitas (no precisa cuáles son, por lo que hay que entender que se refiere genéricamente a los pecados), así como la obligación de asistir a misa, con una serie de matizaciones, como es su integridad ("missam integram") y los días exigidos ("diebus dominicis et festis in sanctis constitutis"). El conjunto de tales obligaciones está tamizado por la adver-

33. "Obedecer e cumplir los mandamientos de los prelados e mayores ecclesiasticos e seglares. E honrrarles a cada uno en su estado" (HT 16v)... "Ha de ayunar la quaresma" (HT 17v)... "Ha de pagar diezmos de toda cosa que nuestro señor da o acrescienta" (HT 17r)..."Honrrar las cosas sagradas: y las yglesias y ciminterios: y non tractar ni hazer alli cosa seglar" (HT 175-v)..."Ha de confessar e de comulgar cada año" (HT 14v).

34. Sin embargo, A. LÄPPLE, Breve historia de la catequesis, Madrid, CCS, 1988, 58 y 63 se centra únicamente en el papel educador de los padres, omitiendo el de los padrinos. 
tencia de que no se trata de obligaciones absolutas y insustituibles, pues "nemo tamen ad impossibile tenetur".

El $3^{\circ}$ mandamiento habla del ayuno cuaresmal, así como el de otros días señalados, con los límites de edad estipulados ("supra XXI anno et infra LXX"), dejando a salvo las situaciones excepcionales en que exista una razón que lo impida ("si non habet legitimum impedimentum").

El $4^{\circ}$ mandamiento recuerda la exigencia de la confesión anual, pero introduce una patente distinción entre la situación de los varones y las mujeres: en principio señala la situación compartida de llegar a la edad de la discreción ("ad annos distincionis"), concepto que no es -o no aparece como equivalente de "ad hetatem legitimam" (línea 33)-; pero cuando se trata de establecer cuál es la edad de la discrección ésta se sitúa en los 24 años para los varones ("masculus ad XXIIII"), mientras que la rebaja a la mitad para las hembras ("femina vero ad XII"). La más elemental observación lleva a afirmar el carácter más precoz y despierto de las muchachas que de los muchachos en torno a la preadolescencia, por lo que no había nada que objetar respecto al tope de 12 años señalados para las chicas; pero elevarlo hasta el doble para el caso de los varones parece -desde la óptica actual- una evidente exageración, incluso en el caso de querer dejar perfectamente establecida la superioridad del varón respecto a la mujer en la mentalidad medieval ${ }^{35}$.

El $5^{\circ}$ mandamiento menciona la exigencia de la comunión pascual, de acuerdo con el criterio anterior de la edad de la discreción; aunque se han de tener en cuenta dos variables: el consejo del confesor prudente; y la oscilación en la edad previamente estipulada, en función de la diferencia de capacidad individual ("secundum rationem et ignorantiam").

Salvando la cuestión de la abultada diferencia entre varones y mujeres para hablar de la suficiente discreción y responsabilidad (o teniendo en cuenta el más que probable error del amanuense), el conjunto de los mandamientos de la Iglesia aparece como un bloque no precisamente rígido, sino adaptable a la situación personal del cristiano no meramente desde caprichosos criterios subjetivos, sino desde la necesaria adaptación a las personas.

35. Habría que pensar más bien en un error del amanuense, quien, sin embargo, ha escrito con absoluta claridad "masculus ad XXIIII". Para ello me apoyo en el hecho de que el catecismo de Pedro de Cuéllar (f. 33v-34r) dice: "La hedat para casar es XIIII' años e en el varon, XII en la muger; quanto para hacer desposajas siete años en el uno e en el otro".. No parece lógico que se sitúe la edad para el matrimonio en otro texto medieval en 14 y 12 años respectivamente, y en cambio los topes sean 24 y 12 años para el caso de la confesión anual. 


\section{Sacramentos.}

La presentación de los sacramentos vuelve a adoptar el estilo conciso que caracteriza el conjunto del Catecismo. Consiste en la enumeración de cada uno de los sacramentos, seguida de una breve aclaración sobre su necesidad, que se diversifica en dos posibilidades: la necesidad de la recepción a nivel personal la ciñe a los sacramentos de bautismo, penitencia y eucaristía; la necesidad de recepción a nivel colectivo, y no obligatoria a título personal, la remarca para el matrimonio y el orden ("quia in ecclesia oportet esse clericos, sive sacerdotem, et coniugatos"). Llama la atención que no haga ningún tipo de manifestación acerca de la necesidad, conveniencia o simple oportunidad de recibir los sacramentos de confirmación y unción de enfermos, como si con el hecho de haberlos recordado en la lista inicial resultase ya suficiente. En este caso, además, tampoco hace referencia al verso recapitulativo que otros catecismos ofrecen ${ }^{36}$.

Resulta más difícil la comparación con otros catecismos medievales en relación con la materia de los sacramentos por el hecho de que la diversidad en el tratamiento resulta grande en los diversos catecismos que he manejado. Esta va desde la exposición breve (SF 298) hasta la exposición realmente amplia (GA 102r), o muy amplia (PC 11v-37r). Precisamente por ello, me limito a establecer la comparación con relación a la exigencia o necesidad de recibir los sacramentos, ya que mientras este Catecismo urge el bautismo, penitencia y eucaristía, otros catecismos hablan de la necesidad de recibir los cinco primeros (SF 298; PC 36r), en lo que se aprecia una divergencia notable con el que nos ocupa; el hecho de que ninguno de ellos dé razones para justificar su respectiva postura hace que la cuestión pueda ser entendida de las formas más diversas, ya que el abanico discurre desde la más absoluta exigencia hasta la permisividad o la devoción personal, cuando resulta claro que hay que tener en cuenta una serie de obligadas precisiones como son la voluntad de recibirlos, la posibilidad de hacerlo, o la edad de la persona a que se refieran. Pero un texto tan escueto como éste no desciende a semejantes puntualizaciones.

\section{Dones del Espíritu Santo.}

Del resto de los catecismos medievales cotejados, únicamente el de Pedro de Cuéllar (PC 52r-v) se ocupa también de la cuestión de los dones

36. "Abluo, firmo, cibo, pigeo, ungit, ordinat, uxor" (GA 102r); "Abluo, firmo, pinget, uxor, ordinat, ungit" (PC 36r); "Abluo, firmo, penitet, cibo, ordinat, uxor, unxit" (HL 296v). Nótese que en el caso del verso del catecismo de Pedro de Cuéllar, hay una omisión (¿cibo, edo?) quedando el verso constituido por seis miembros. 
del Espíritu Santo. Ambos los enuncian exactamente en el mismo orden (aunque después, al explicarlos, el de Pedro de Cuéllar no respete el orden propuesto). Pero lo que realmente llama la atención es el inexplicable y nada lógico antagonismo que nuestro Catecismo establece entre tales dones y los pecados capitales, señalando a cada uno de estos dones un pecado capital al cual se opone. Llama la atención por tres razones: $1^{a}$, porque ningún otro catecismo que yo conozca, ni antiguo ni moderno hace algo parecido; $2^{\mathrm{a}}$, porque no se alcanza a ver la oposición coherente que pueda existir entre cada don y el pecado al que lo enfrenta; $3^{\mathrm{a}}$, porque parece desconocer lo que va a enunciar unas líneas más adelante (líneas 67-74) sobre los pecados capitales y las virtudes contrarias a ellos.

Pese a semejante extrañeza, voy a desmenuzar las propuestas del Catecismo. Es claro que se puede encontrar en algunos casos una cierta "lógica" en las antítesis establecidas, en función del contenido que se quiera dar a cada uno de los conceptos, puesto que no resulta excesivamente difícil afirmar que el hombre piadoso tiene que evitar la envidia ("pietas...spellit invidiam"). Pero llevar las cosas al extremo de afirmar que el hombre prudente en el consejo por eso mismo huye de la avaricia ("consilium... spellit avaritiam"), o que el inteligente se ve a salvo de la gula ("intelectum...spellit gullam"), resulta carente de toda explicación que no sea la de un craso y reiterado error cometido por el copista o por el autor del Catecismo; obliga en cualquier caso a forzar el sentido natural de los conceptos para rebuscar razones sutiles y retorcidas, puesto que lo contrario de la avaricia, entendida como defecto o pecado, es la generosidad o el desprendimiento, según el más normal de los sentidos. No resulta fácil sospechar cómo se ha podido cometer tan burda equivocación, por sí misma suficientemente llamativa.

No habría que añadir más que una breve consideración a la excepcional formulación que hace de la ira, a la que adjunta una especie de definición: "Iram, que est quedam stultitia" (La ira es una.tontería, una necedad). ¿Qué ha querido decir el autor especialmente?, ¿por qué esta coletilla?, ¿no se podría decir lo mismo del resto de los pecados capitales?. Parece que se puede sospechar en este caso la voluntad de combatir a quien desee persistir en el aludido error, pues contrapone la necedad al don de la ciencia ("Donum sciencie", el único precedido con el substantivo "donum") tratando de aducir razones que justifiquen tan arbitraria distribución.

\section{Virtudes cardinales.}

En nuestro Catecismo las virtudes cardinales aparecen con una presentación que en cierto modo resulta original: enumera las cuatro virtudes corres- 
pondientes acompañando a cada una de una especie de definición, más o menos acertada. Sin embargo, hay que notar de entrada que el texto incluye un manifiesto error al confundir "prudentia" con "providencia", como aparece escrito, lo que revela que el amanuense no distinguía demasiado lo que tenía que ir escribiendo y le daba tanto lo uno como lo otro.

Respecto a las propuestas de definición que acompañan a cada una de las virtudes, la que literalmente sigue a "providencia" (en lugar de "prudentia") aparece en realidad como una definición incompleta, ya que el texto señala "qua homo nichil ap(petit)"; con lo cual, ad sensum, la prudencia ayuda al hombre a no apetecer nada: resulta una definición extravagante y escasamente precisa de prudencia. Parecida definición aparece en la virtud siguiente, "temperancia, qua homo nichil appetit, unde fit penitens": si el primer miembro de la definición resulta igualmente impreciso, el segundo trata de completar la escasa claridad al volver a decir que el hombre templado no apetece nada, y deviene penitente, aunque en rigor la templanza señala otro tipo de conducta en el hombre que posee esta virtud. A diferencia de las anteriores, las definiciones que acompañan a la fortaleza y a la justicia resultan mucho más ajustadas, dentro de su brevedad ("Fortitudo, quae est firmitas contra adversa; Iustitia que est virtus sua unicuique reddere"). El conjunto de tal exposición resulta, pues, irregular, falto de rigor, y especialmente en las dos primeras virtudes, lo suficientemente genérico como para llegar a la conclusión de una muy escasa cualificación teológica y catequética, aunque sea capaz de corregirlo en el caso de las otras dos virtudes.

El resto de los catecismos medievales cotejados no aportan datos especialmente relevantes, excepción hecha de un cierto parecido existente en los catecismos de Gutierre de Toledo (GT,98) y Gil de Albornoz (GA 103r), que resulta más patente en la defición de justicia: "A esta pertenece dar a cada uno lo suyo".

\section{Virtudes teologales.}

La enumeración no puede ser más escueta, y, sin embargo, aporta algunos datos significativos. El primer lugar es preciso fijar la atención en el mismo adjetivo con que califica a estas virtudes, que no es el moderno y usual "teologales", sino el de "theologice". En este tipo de denominación coincide, curiosamente, con la que emplea el catecismo de Juan de Aragón que las llama también "virtutes theologice" 37 , y con el de Gutierre de Tole-

37. "Super omnes has autem virtutes morales supernium obtinet locum et gradum virtutes theologice, que sic dicuntur a theos quos est Deus..." $(273 \mathrm{v}, \mathrm{b})$. Además de esta explicación global sobre el nombre, el catecismo prosigue con una exposición amplia sobre cada una de ellas. Al desarrollar la cuestión de la caridad, coincide también con este Catecismo al afir- 
do, para el cual son "virtudes teológicas e divinales" (GT 98-99), aunque se limite a hacer una descripción muy breve parecida a la de Gil de Albornoz ${ }^{38}$.

El segundo dato que conviene destacar es la expresa referencia a 1 Cor. 13,13 , repitiendo casi textualmente las palabras de la Vulgata, cosa que hace literalmente el catecismo de Juan de Aragón, más exacto en este punto que el texto analizado ${ }^{39}$.

\section{Pecados capitales.}

Estos son enumerados en nuestro Catecismo con la denominación usual, además de poner en paralelo, también con la denominación usual, las virtudes contrarias correspondientes. Ya he manifestado la falta de lógica que tiene el presentar los pecados capitales en dos ocasiones casi seguidas, opuestos en un caso a los dones del Espíritu Santo y en otro caso, situados frente a una serie de virtudes, como suele ser normal en los catecismos. Aceptando el error en el formulario anterior, hay que reconocer el adecuado planteamiento del formulario actual, que viene reforzado con la expresión "contraria pecatis mortalibus". La doble denominación que figura ("vicia capitalia"; "pecatis mortalibus") no tiene nada de particular pues ambas resultan intercambiables, aunque haya que señalar en los textos antiguos con más frecuencia el uso de "pecados mortales" que el de "pecados o vicios capitales".

La doble lista de pecados y virtudes es escueta, pues carece de todo tipo de explicaciones o aclaraciones complementarias. Habría que advertir únicamente que no todos los catecismos utilizan con exactitud las mismas expresiones para designar los vicios o las virtudes respectivas, por lo que hay entre unos y otros un ligero desplazamiento en los acentos que se den a las palabras respectivas ${ }^{40}$.

Varios de estos catecismos medievales condensan el aprendizaje de los pecados capitales en la palabra mnemónica "Saligia"41, compuesta con las

mar la preeminencia sobre las otras virtudes: "Karitas quam apostolus omnibus predictis et aliis virtutibus profert dicens, 'Nunc manent fides, spes, karitas tria hec, maior autem horum est caritas"" (274r,a).

38. Al ocuparse de ellas (GA 103r-v), las llama con la denominación similar a las anteriormente descritas de "virtudes teólogas".

39. Pedro de Cuéllar 50r-51v expone conjuntamente, y por este orden las virtudes teologales y cardinales, al término de cuya exposición, las propone en conjunto como virtudes opuestas a los pecados capitales, apartándose con ello de la práctica usual, que opone a los pecados capitales otra serie de virtudes distintas de las teologales y cardinales.

40. Por ejemplo, GA 103v habla de "sanna" (=saña) y de "yra", en lugar de "invidia", y "mansedumbre" en lugar de "amor proximi"; o "garganteria" en lugar de "gula". (Los mismos términos emplea Gutierre de Toledo, excepto el de "yra", pues usa dos veces "sanna").

41. GA 103v; JA 273r,a; HL 297v; PC 52v. 
iniciales de cada uno de los pecados, para que más fácilmente pueda ser retenida la lista completa de todos ellos. Este Catecismo, que en otras ocasiones ha recurrido a versos recapitulativos comunes a los textos medievales, no hace uso en esta ocasión de tal palabra.

\section{Sentidos corporales.}

El Catecismo se limita a la mera enumeración de la lista tradicional de los sentidos corporales, sin añadir ningún tipo de explicación. Hay que señalar, con todo, que es una enumeración no frecuente, ya que únicamente la he encontrado en el catecismo hispano-latino (HL 299v) el cual pone los sentidos en el mismo orden, añadiendo, además una palabra mnemónica "Vagot", formada por las iniciales de cada uno de los sentidos en su denominación latina, y que a continuación explica. En el caso presente, prescinde de la apoyatura mnemónica y se limita a la mera enumeración.

\section{Potencias del alma.}

Es el único catecismo medieval que conozco que incluya en sus páginas el presente apartado (relativamente frecuente en catecismos posteriores). De aquí que haya que señalar no tanto la enumeración de las tres potencias ("memoria, intelectus et voluntas"), sino el hecho singular de destacar por ello respecto al resto de losicatecismos de la misma época, por lo que resulta enteramente original en este punto.

\section{Vestidos espirituales y del alma.}

Hay que hacer la misma afirmación que en el caso anterior, pues tampoco este apartado presenta paralelismo alguno, ni próximo ni remoto, con otro cualquiera de los catecismos consultados.

La misma denominación utilizada resulta algo confusa en la redacción al proponer dos substantivos vinculados con la preposición "ac"; parece que trata de dar el mismo valor a la expresión "vestidos espirituales" que a la de "vestidos del alma", efectuando una rara mezcla de ambas. Igualmente rara es la designación, con ribetes espirituales, de tal forma de proceder en el cristianismo, pues no se corresponde con las expresiones parecidas de Rom. 13, 12; Ef. 4, 24; Ef. 6, 11,... que invitan a revestirse del hombre nuevo, o a ajustarse las armas para el combate espiritual.

Las que el Catecismo propone son "innocentia", "matrimonialis castitas" y "spiritualis matrimonium anime", que tienen el denominador común de proponer un ideal cristiano de castidad como la forma más perfecta de vivir 
el cristianismo, con lo que supone de desprecio o minusvaloración de la vida conyugal. La tercera de las expresiones precedentes, resulta, además, confusa en la redacción completa pues dice con claridad "spiritualis matrimonium anime est nomen dei" (no "in nomine dei") identificando" el matrimonio espiritual del alma" con "el nombre de Dios", lo cual resulta de difícil comprensión. La justificación evangélica posterior ("non ex solo pane vivit homo") parece que ha de referirse a los tres supuestos que acaba de plantear, como una afirmación de índole espiritual que invita a no poner la meta únicamente en los placeres de la vida matrimonial, pues existe además la posibilidad de renunciar voluntariamente a ella; es una aspiración a la perfección evangélica, que, sin embargo, no aparece expresamente consignada en el texto.

\section{Consejos evangelicos.}

El último apartado del Compendium de Doctrina Christiana está dedicado a los consejos evangélicos ("consilia iesu christi ad quae tenentur viri perfecti"). Igual que hemos visto en otros casos, el apartado anuncia una división en cuatro partes, que después no cumple; los cuatro consejos que promete, pueden quedar reducidos a dos o, todo lo más, a tres. Remite a Mt 5,39 cuando habla de "mansuetudo et profunda humilitas", como actitud no violenta de quien está dispuesto a soportar las injurias y afrentas por contener la ira (mansedumbre) y por evitar el enojo (humildad). En el caso de desdoblar lo que parece uno por el sentido, tendríamos aquí dos de los cuatro consejos evangélicos prometidos.

El otro es la "paupertas spiritu", fundamentado en la referencia bíblica de Mt 19,21 como disponibilidad para el desprendimiento de los bienes. Llama la atención que no emplee la expresión "perfecto", que emplea el texto bíblico en cuestión, y que, al contrario, al emplear la expresión "pobre de espíritu" no haya aludido a Mt. 5,3 que parecería lo natural, ya que en esta ocasión reproduce los textos bíblicos. Sin embargo, tradicionalmente se ha considerado como referencia bíblica fundante del consejo evangélico de la pobreza el texto de Mt 19,21, y por ello el autor entiende que da lo mismo hablar de "perfectio" que de "paupertas spiritu", pues en su mente está claro el pensamiento que trata de transmitir. Este sería el segundo (o, admitiendo el desdoble anterior, el tercer) consejo evangélico que el Catecismo propone.

El texto no se encuentra mutilado, ni tachado, ni dejado en blanco y posteriormente omitido por olvido. Más bien parece tratarse de un despiste, puesto que el manuscrito cubre perfectamente la caja que el amanuense se ha trazado, para pasar, sin solución de continuidad en la página siguiente 
(f. 143r) a desarrollar el calendario litúrgico a que hice alusión en la presentación del manuscrito. Por tanto, la exposición de los consejos evangélicos queda incompleta con la presentación de dos (o tres). Es una lástima, porque bien podría decirse que es uno de los "trataditos" del Catecismo más logrados no tanto por su extensión, cuanto por el enraizamiento bíblico que manifiestan con la cita literal del texto bíblico.

\section{ORATIONES}

La segunda parte del Catecismo la constituyen tres breves oraciones o jaculatorias, con su explicación aneja de las indulgencias concedidas, más una fórmula de absolución sacramental, que ocupan íntegro el f. 145v.

\section{Oraciones.}

Son tres breves oraciones compuestas con el mismo esquema sintáctico: invocación a Jesús, expresión de adoración por un sufrimiento de los que constituyeron su pasión, y petición de protección precisamente por el sufrimiento que ha sido puesto de relieve. Las tres oraciones guardan una unidad estilística perfecta que invita a no fragmentar el conjunto sino a mantenerlo con el ritmo y la cadencia que las tres oraciones marcan, pues, con brevedad, van haciendo un recorrido por algunos de los aspectos de la pasión, como si de un "via crucis" abreviado se tratara. La primera oración se centra en la cruz de la que pende Jesús, pidiéndole que esa misma cruz sea causa de salvación (la palabra se repite dos veces, una en la invocación "in cruce pendentem", y otra en la petición "tua crux liberet me"). La segunda oración hace lo propio con las heridas de Jesús ("in cruce vulneratum", en el primer miembro, y "tua vulnera sint remedium", en el segundo). La tercera oración casi coincide en tal repetición puesto que alude en primer lugar al sepulcro ("in sepulcro positum"), y luego a la muerte como término prácticamente equivalente ("tua mors sit vita mea").

En los tres casos, además, añade otro recuerdo de la pasión que acompaña a cada uno de los sufrimientos primariamente enunciados: "in cruce pendentem, coronam spineam in capite portantem", para la primera de las oraciones; "in cruce vulneratum, felle et aceto potatum", en el segundo caso; y "in sepulcro positum, aromatibusque conditum", para la última jaculatoria. Habría que anotar, finalmente, que (¿despiste del amanuense?) las oraciones segunda y tercera incluyen un "amen" postrero, ausente en el caso de la 
primera. Estilísticamente se aprecia una elegante construcción latina, depurada, que denota con toda probabilidad una rancia tradición de la que el Catecismo se hace eco recogiendo en sus páginas algo que bien podría remontarse años o siglos atrás. La única sombra del conjunto es la deficiente grafía "anime mee", usual en la fecha tardía de la redacción.

En el caso de la primera oración termina haciendo una velada alusión bíblica al concluir "liberet me a percutiente angelo": el angel exterminador. Tal referencia aparece con claridad en Is. 37,36: "Egressus est autem angelus Domini et percussit in castris Assyriorum centum octoginta quinque milia". Aunque no tendría nada de particular que tuviera presente el pasaje de la pascua vivida en Egipto por el pueblo de Israel en que el propio Dios pasará descargando su ira contra el pueblo egipcio: "Et transibo per terram Aegypti nocte illa, percutiamque omne primogenitum" (Ex. 12, 12); "Transibit enim Dominus percutiens Aegyptios..." (Ex. 12, 23).

Las oraciones se completan con la exposición de las indulgencias concedidas, resultando cuando menos curioso que tales indulgencias haya que obtenerlas por la recitación de estas oraciones y de cinco padrenuestros, ante una imagen de Cristo resucitado ("iesu christi quando exivit de sepulcro"), en tanto que las oraciones están haciendo referencia a la pasión, muerte y sepultura, pero no a la resurrección, con lo que parece que la forma de obtención de las indulgencias no se adecúa plenamente al sentido de las jaculatorias. La concesión de las indulgencias alude a San Gregorio ("beato gregorio"), sin que se pueda precisar de cuál de los papas de este nombre se quiere hacer mención. Y por último remite con toda claridad a una práctica típicamente romana ("ut patet in urbe rome"), en uno de cuyos conventos, no identificado, se localiza la concesión de las indulgencias referidas. Es una muestra clara del origen de estas jaculatorias, y, quizá también, del Catecismo.

\section{Absolución.}

La fórmula de absolución penitencial que sigue a las jaculatorias anteriores completa el f. $145 \mathrm{v}$. Como el conjunto del manuscrito no sigue un orden perfectamente lógico, nada tiene de particular que aparezca aquí, y no en el contexto del sacramento de la penitencia, la fórmula de absolución. Puesto que tal fórmula ritual ha variado en la práctica pastoral con el paso del tiempo y en los diversos lugares, resulta difícil rastrear su origen o su cronología. Sí parece claro que hay que inscribirla en el conjunto de las fórmulas llamadas indicativas (o prescriptivas, o judiciales), en lugar del otro gran bloque de fórmulas penitenciales optativas $u$ oracionales. 
Se trata, en efecto, de la proclamación de una sentencia. Tales "fórmulas indicativas aparecen en los siglos IX-X y son después las más preferidas en la práctica pastoral con el favor de las escuelas, como más conformes con el carácter judicial de la actio poenitentiae y más en analogía con las otras fórmulas del bautismo y de la confirmación"42. La aproximación cronológica de tratarse de una fórmula posterior a los siglos IX-X, recogida en un manuscrito del $\mathrm{XV}$, deja un márgen demasiado amplio para concretar con mayor precisión.

La absolución en cuanto tal está constituida por cinco miembros: 1) Declaración de la potestad absolutoria en nombre de Jesús: "Dominus iesus christus ipse te absolvat et ego te absolvo autoritate qua fungor" ; 2) Levantamiento de la pena de excomunión, y readmisión a los sacramentos: "Et iterum te absolvo ab omni vinculo excomunicationis. Et restituo te in VIIem sacramentis eclesie"; 3) Proclamación de los efectos salutíferos del perdón: "Et iterum te absolvo ab omnibus peccatis tuis michi confessis et oblitis et omnia bona quae fecisti sint ad laudem dei in remissionem peccatorum tuorum. Amen"; 4) Recomendaciones pastorales: "Dic pater noster, fac penitentiam, vade in pace et amplius nolli peccare"; 5) Despedida del penitente en el nombre del Señor: "In nomine patris et filii et spiritus sancti. Amen". (Este último miembro también podría considerarse como conclusión del primero, habiéndose introducido entre medias los numerados como 2,3 y 4 ).

Es patente el paralelismo que existe en la construcción de está fórmula de absolución y la del ritual del cardenal Santoro, con repetición de algunas expresiones casi literalmente en los miembros 1,2 y 5 , y con omisión de los apartados 3 y 4 . La fórmula del cardenal Santoro dice: "Dominus noster Iesus Christus te absolvat, et ego auctoritate ipsius te absolvo [ $1^{\circ}$ miembro] ab omni vinculo excommunicationis maioris vel minoris, suspensionis et interdicti, in quantum possum et tu indiges, et restituo te unitati et communioni fidelium et sanctis sacramentis Ecclesiae [ $2^{\circ}$ miembro]. Iterum ego te absolvo ab omnibus peccatis tuis in nomine Patris et Filii et Spiritus Sancti. Amen" $\left[5^{\circ} \text { miembro }\right]^{43}$. Esta fórmula penitencial del cardenal Santoro está datada en 1523, lo que no es óbice para que anteriormente se estuviera empleando otra fórmula como la del Catecismo parecida, pero no igual, con lo cual el problema de la cronología del presente manuscrito sigue planteado en los mismos términos.

42. M. RighetTI, Historia de la liturgia, Madrid, BAC, II, 1956, 852.

43. M. RighetT, o.c., 853. Advierte que "suspensionis" ha de omitirse para los laicos, según señala la rública, así como también que se ejecute la señal de la cruz sobre el penitente al pronunciar las palabras finales. 


\section{CONFESSIO DEVOTISSIMA FRATRIS JOHANIS DE MARCHIA.}

Como ya advertí al presentar conjuntamente el contenido del Catecismo la Confessio tiene el título en latín, pero el resto de la misma se encuentra escrito en italiano.

Hay que inscribirlo en la serie de confesionales del medievo, con un alto contenido catequético, aunque la intención primera sea la de preparar y llevar a cabo adecuadamente la celebración de la penitencia. Todavía se acentúa más el aspecto catequético de la Confessio comprobando que, en un determinado momento, al presentar los artículos de la fe, abandona el estilo penitencial de las preguntas que disponen para la manifestación de los pecados, y opta claramente por el tono catequético de la simple exposición o enumeración de los artículos según el orden del credo.

Como tal confesional, va inquiriendo a través de las preguntas las posibles transgresiones de la conducta cristiana que se han llevado a cabo. Pero en ocasiones abandona esta perspectiva para pasar a afirmar en el sentido de hacer una calificación moral de ciertos pecados (en la lujuria, línea 237; en el sentido del tacto, línea 334; en las virtudes teológicas, líneas 382), manifestando en todos los casos la calificación moral de pecado grave. Tan sólo en un momento aparece la mitigación moral de un pecado (línea 276), y en cambio en el apartado dedicado a contemplar las circunstancias que rodean los pecados no se habla de circunstancias atenuantes que puedan disminuir la culpabilidad, por lo que parece que hay que deducir que no parece tener voluntad justamente exculpativa, sino que en prácticamente todos los casos se inclina por el rigorismo moral.

\section{Disposiciones para la confesión.}

Al comienzo de este apartado manifiesta el autor, Juan de la Marca, que lo que pretende es facilitar una mejor y más perfecta confesión. Expresamente dice que divide el tratado en doce partes ("poneremo XII articuli et regule neccesarie ad la nostra confessione"), pero después encontramos que las tales doce partes no aparecen, pues incluyendo como una parte la introducción sobre las disposiciones para la confesión, y además el apartado final sobre las circunstancias de los pecados, salen en total once, y no doce partes.

Esta primera parte sobre las disposiciones o preparación para la confesión la subdivide en doce reglas ("E nonche sono XII li preparacioni", línea 118-119), que va enumerando a continuación, con la particularidad de que funde la $5^{\mathrm{a}}$ y la $6^{\mathrm{a}}$ en una ("La quinta e la sexta si he in quanti luochi ay fati li peccati”), que apunta a una sola circunstancia y que no resulta fácil desdo- 
blar en dos aspectos diversos a tener en cuenta: parece como si en la mente del autor estuvieran ambas lo suficientemente claras como para no tener necesidad de repetirlas o recordarlas más que fundidas en una.

Estas disposiciones preparatorias, lo son en parte, mientras que por otro lado se centran en las circunstancias de los pecados que volverán a ser contempladas en la última parte de la Confessio.

\section{Pecados capitales.}

Al igual que apareció en el Compendium, en que denominaba "pecata mortalia" (línea 75, además de "vitia capitalia" en la línea 71) aquí los llama "peccati mortali", según la denominación comunmente utilizada.

* Soberbia.

Se encuentran resonancias evangélicas cuando señala en la línea 138-139 "se ay voluto esere servuto et non servir" que aluden a Mt. 20,28: "Filius hominis non venit ministrari, sed ministrare". Está muy atinada la observación, formulada por partida doble de avergonzarse de los parientes pobres ("Se te ay vergognato deli parenti poveri", línea 144-145), o de las personas pobres ("Se ay fato vergognia a le povere persone", línea 146). En cambio, la última pregunta que formula en el apartado sobre la soberbia ("Se ay retenuta la possessione de altri iniustamente", línea 147) está evidentemente fuera de lugar, pues debería estar ubicada en la avaricia, donde hace dos preguntas equivalentes ("Se ay posedute dote, o vero possessione de altri", línea 191192; "Se ay tenuta la cosa che te e stata prestata", línea 197-198), que ciertamente están en el contexto adecuado. La primera pregunta de las formuladas sobre la soberbia, apenas llama la atención: "Se ay despreçata alcuna persona" (línea 133); quiero, sin embargo destacarla, por el gran parecido de fondo que contiene con la parte correspondiente al confesional que está incluído en el catecismo de Pedro de Cuéllar al abordar entre los sacramentos la cuestión de la penitencia. Instruye al confesor para que haga algunas averiguaciones sobre los pecados cometidos, y concretamente sobre la soberbia: "Si despreciaste a otro porque non era tan bueno commo tú" (PC 20v).

* Envidia.

Unicamente vale la pena destacar la pregunta sobre "se ay dapnificato al amo per invidia" (línea 150), en la que parece que el contexto invita a poner el acento en la falta de envidia que se comete, olvidando la cuestión de justicia que resulta lesionada al damnificar a otro. Además, las dos primeras preguntas en el apartado sobre la envidia ("Se ay avuta tristicia del beni de 
altrui, o vero malanconia. Se te sei alegrato del mal d'altrui", línea 149-150) tiene parecido con la interrogación del confesional de Pedro de Cuéllar: “¿Pesóte nunca del bien e plógote del mal de otro por enbidia?” (PC 20v).

* Ira.

Similar a la situación anterior aludida en la envidia, al tratar de la ira vuelve a producirse una pregunta parecida: "Se con ira manifestasti cosa secreta" (línea 159-160), dando la sensación de que lo malo es hacerlo con ira, y que al desvelar una cosa secreta no se contraviene el octavo mandamiento (que, por cierto, no contempla este supuesto). También llama la atención la pregunta que hace: "se te conturbi quando non te fato honore" (línea 167), que casi viene a repetir la que había formulado a propósito de la soberbia: "se ay voluto... essere honorato et non honorar" (línea 139).

* Pereza.

La primera pregunta sobre la pereza versa sobre la dejadez al cumplir los deberes religiosos, con un evidente parecido con la pregunta correspondiente del catecismo de Pedro de Cuéllar: "¿dexaste algunas vegadas de yr a la yglesia por pereza? (PC 21r). Llama la atención la pregunta de la línea 172: "se ay la mente con le cose desoneste", que en realidad debería ser trasladada a la parte correspondiente a la lujuria, aunque la pereza o la desocupación puedan ser la causa circunstancial. Por la misma razón, la pregunta sobre la negligencia en atender a los pobres ("Se sey negligente ad visitar le infirme et li poveri", línea 177-178) podría estar perfectamente situada entre las obras de misericordia corporales, que contempla más adelante. Otro tanto habría que decir de la pregunta: "se ay pregato dio che te facia la vendeta" (línea 181-182), que tendría que estar entre las correspondientes a la ira, más que a la pereza.

Las preguntas acerca de los esfuerzos por encontrar un buen confesor, y por examinar la conciencia (líneas 180-181) vienen a resultar la repetición en forma pecaminosa, por omisión, de las recomendaciones que había hecho antes de la confesión: "La decima si he fa che trove diligentemente el buono confessore... La undecima he che denanti che te confessi examina molto bene la constientia", (líneas 126-128), de manera que es urgido doblemente como disposición para la penitencia, y como manifestación de pecado de pereza.

* Avaricia.

La primera pregunta que figura al hablar de la avaricia ("Se ay fatta mai luxuria", línea 184) resulta evidentemente fuera de lugar. En la línea 189 se 
menciona expresamente la usura, tan duramente combatida por la Iglesia a lo largo de la Edad Media, por los múltiples abusos y vejaciones a que daba lugar, algunos de los cuales están perfectamente definidos en las preguntas de la Confessio como formas de incurrir en el pecado de avaricia ${ }^{44}$.

Hay que destacar el claro contenido bíblico y la notable demanda de justicia contenidos en la pregunta: "Se ay retinuto salario a li toy lavoratori (línea 192-193), o en la extraordinariamente bien formulada: "Se ay dato piu presto lo pane al cane che al povero" (línea 196-197) 45 . Una de las preguntas es reflejo perfecto de la situación de inseguridad que por tierra, pero sobre todo por mar, se vivía en la Edad Media con la esclavitud por parte de los musulmanes: "Se sey stato adiutore de capture deli infideli contra li christiani, o vero ce ay consentito" (línea 200-201).

La pregunta: "Se ay mutati li termini de li terre" (línea 203) encuentra su paralelismo en otra de la parte de confesional incluído en el catecismo de Pedro de Cuéllar, que denota una inveterada práctica de apropiarse del terreno ajeno por el procedimiento de desplazar los mojones de su lugar: "o tiraste los mojones de los términos de las tierras? (PC 21r).

Despista de alguna manera la requisitoria: "Se sei stato arbitro et ay dato mala sentencia" (línea 203-204), que únicamente puede ser entendida en el contexto de la avaricia suponiendo que la mala sentencia obedece a una prevaricación previamente pactada en términos económicos en beneficio del juez.

* Gula.

Resulta llamativa para la práctica actual la prohibición de comer queso o leche ("Se ay magnato caso o latte", línea 214) en los días de ayuno, pero queda constancia de la práctica usual en el momento de la redacción de la Confessio. Igualmente llama la atención la prohibición de comer antes de oír misa el domingo ("Se ay magnato nanti che ay odito la messa le domenica", línea 218-219), a no ser -cosa que aquí no dice- en caso de pretender comulgar, como hace en la línea 221-222. La formulación de la pregunta de la línea 215: "Se si stato inbriaco" es prácticamente igual que la del confesional

44. Con. Lateranense II, canon 2 , el año 1139 (D 716); Ep. de Gregorio IX "In civitate tua", posterior a 1179 (D 753); Ep. de Urbano III “Consuluit nos" (D 764); Con. Viennense, sessio III, constit. "Ex gravi nos", de 1312 (D 906). El breve confesional incluido en el catecismo de Pedro de Cuéllar pregunta a este respecto: “¿Fuste usurario? (PC 21r).

45. Resulta mucho más incisiva y clara la formulación de la Confessio que la que se encuentra en la parte de confesional del catecismo de Pedro de Cuéllar, en que dice en torno a la misma idea: "¿non ayuneste tú muy bien e farteste los pobres que lo andavan demandando muriendo de fanbre?" (PC 21r). 
incluido en el catecismo de Pedro de Cuéllar: "si fuiste embriago" (PC 21r), con evidente paralelismo en fondo y forma.

Durante mucho tiempo, con una consideración peyorativa del matrimonio, y con una valoración excelsa de la eucaristía, se consideró pecado el ir a comulgar sin haber practicado la abstinencia sexual, de lo cual, la Confessio muestra un claro testimonio, añadiendo, además, la abstinencia sexual en los días siguientes: "Se per tre di nanti et tre dipoi che te si comunicato non te si abstenuto del matrimonio" (línea 222-223) ${ }^{46}$. Asimismo, estaba prohibido comer manjares propios de judíos: "Se ay magnate cose da iudei" (línea 223), acaso por el riesgo de excesiva confraternización que pudiera derivar en la apostasía. La comida se convierte en un instrumento de identificación de la propia fe y de la comunidad a que se pertenece, especialmente en los lugares en que la prolongada convivencia puede inducir a la relajación de las costumbres. Comer al estilo judío, o comer alimentos preparados según otros patrones o recetas no sólo es mal visto, sino que además es considerado como pecaminoso por el confesional ${ }^{47}$.

46. Contra lo que a primera vista se podría pensar, no se trata únicamente de una deformación o anticuada visión medieval, puesto que hay testimonios de ello, tanto en el catecismo de Trento, como en otros más recientes, hasta llegar al presente siglo. Resultaba envuelta en la nebulosa tanto la condición de casados como la profesión de comerciantes, pues en ambos casos la inclinación al mal era patente. Ver L. RESINES, La fe maltratada, Valladolid, Ed. L. Resines, 1988, 206-207.

47. N. Lopez MARTINEZ, Testificaciones inquisitoriales de mercaderes burgaleses en 1491, en "Burgense" 14 (1973) 1-24 aporta notables datos en este sentido, por el "interés [para] el concepto de vida cristiana laical que estaba en el ambiente (...) Los encausados tratan de demostrar (...) la fiel observancia dominical, la no discriminación de alimentos". Juan Martínez de Astudillo, vicario general del obispado de Burgos recibe el 11 de mayo de 1491 comisión del obispo de Córdoba, D. Iñigo Manrique para que tomara declaración a los testigos del fallecido Pero López de Calatayud, invocados por su hijo Juan, a fin de impugnar la acusación de herejía que contra él argüía el promotor del Santo Oficio. En el interrogatorio, la pregunta $13^{\mathrm{a}}$ se formula así: "Iten si saben quel dicho Pero López toda su vida acostumbró de comer e comió continuamente toçino e cosas de puerco, y perdices ahogadas, y congrio, y pulpos e anguilas, y liebres y conejos, e carne de la carnecería de los xpianos y aun que son defendidas a los judios" (f. 24v); y la 19a: "Iten si saben que todo el año, e tambien quinse dias antes e quinse despues de la pascua de resurreccion de cada un año, masaban en casa del dicho Pedro López o traían de la panadería pan lindo e lo comían segund que lo acostumbraba comer todo el año" (f. 25r). Los testimonios a tales preguntas son: el de María de Butrón: "Comían de todo, como los demás. No rechazaba ningún guiso. Ella los hacía y lo sabe"; "Siempre comía pan lindo, que ella y otras criadas amasaban y cocían para sus amos" (f.30v); y el de Juan de Butrón: "Se ponían berzas con toçino y que comían él y los que estaban a la mesa de ello (...) Lo mismo otros manjares; e aunque viniesen las perdices podridas, que no las desechaba" (f. $41 \mathrm{v}$ ). Interrogatorio y testimonios, respectivamente en o.c., pg. 8 y 12 . 
* Lujuria.

Los requerimientos sobre los pecados en materia de lujuria son minuciosos, pero no es el aspecto de los pecados capitales que contenga más preguntas. Llama la atención que entre los pecados en materia de castidad, al enumerar las circunstancias personales que modifican la clase de pecados, se incluya expresamente el pecado con personas pertenecientes a la raza o religión judía, lo que añade una especial gravedad al hecho pecaminoso ("Se ay peccato con... iudey", línea 230). También pregunta la Confessio por el hecho de acompañar a otros, lo que convierte en cómplices o en inductores del pecado, aunque no se haya llevado a cabo acción alguna (línea 231-232), lo cual conecta con el aspecto que había contemplado en las disposiciones para la confesión, al considerar la compañía de otros como un aspecto a tener en cuenta: "La quarta si he quanti peccati ai conmessi conla compagnia" (línea 122).

Encontramos uno de los casos de calificación expresa de "pecado mortal" con ocasión de la lujuria, con un rigorismo patente, puesto que los hechos que señala no constituyen en sí mismos una violación de los mandamientos de Dios, y no hay que presuponer una malicia manifiesta en tales acciones: "Se per veder l'ammor sey an[d]ato ala chesia, o vero messa ad udir predicha, o vero a la confessione ay pecato mortalmente" (línea 235-327). Además, en este caso, el autor transforma la pregunta en una aseveración.

En cambio, como en otras ocasiones, está fuera de contexto la pregunta: "Se con la mente ay fato omiccidio" (línea 237), que tendría que inscribirse en la ira y no en la lujuria. Resulta muy curiosa la formulación de la pregunta siguiente, que con la repetición de las palabras "Se una dona maritata" denota un error típico del copista que vuelve la vista inadvertidamente a algo que ya ha escrito; pero llama más la atención el fondo de la pregunta: "Se una dona maritata da un figlo aut una figla non legitima comite addulterio" (línea 239-240). De las palabras reproducidas se deduce que el adulterio se comete por el hecho de que una casada de a luz un hijo ilegítimo, trasladando la malicia del acto no al adulterio en sí, sino al posible parto consiguiente; de manera que se deduce que si no tiene lugar el parto, no tiene tampoco lugar el adulterio, lo que equivale a medir el pecado únicamente por sus consecuencias evidentes.

\section{Mandamientos de la ley de Dios.}

* $1^{\circ}$ Mandamiento

El primer mandamiento se inicia con el recordatorio expreso del precep-

to. En la enumeración de los pecados contra el primer mandamiento, ade- 
más de otros supuestos que equivalen a poner en duda afirmaciones de fe, como la existencia de otro mundo, o la inmortalidad del alma, la Confessio se manifiesta radical en el comportamiento con los no cristianos: "Se ay dato consiglo, adiutorio o favore a iudei, o veri infideli, o si laudi lo creator loro" (líneas 253-254); "Se poi defendere lo christiano contra li iudeo et infideli et non defendi" (líneas 254-255). Inevitablemente hay que introducir una serie de matizaciones, ya que no es lo mismo dar un simple consejo, prestar una ayuda o hacer un favor, en plan de mero apoyo humano, sin que por ello se impliquen las respectivas creencias, que el hecho -más grave desde el punto de vista religioso- de alabar a sus "creadores", Moisés o Mahoma, por lo que implica de reconocimiento de la verdad de la otra religión. Parece que la única postura válida para el cristiano es la del insulto y la agresividad hacia los no cristianos, negando la más elemental ayuda. Sin embargo, la práctica de la convivencia diaria -no exenta de problemas e infidelidades- desdecía semejantes afirmaciones pues no eran raras las situaciones de ayuda y apoyo mutuos.

La segunda pregunta va prácticamente en la misma dirección, porque se trata, por principio, de tener que defender a los christianos de los judíos e infieles; ni siquiera se pregunta Juan de la Marca por la posibilidad de que la razón pueda estar de parte del no cristiano, y que antes de ponerse a atacarlo haya que pararse a dilucidar cuál es lo justo y de qué parte está la razón. El asunto no tiene vuelta de hoja y la identidad de cristiano obliga a combatir siempre, y sin excepciones, a judíos e infieles. El autor parece olvidarse, en aras de la espiritualidad, de las múltiples alianzas políticas del Medievo con todo aquel que pudiera prestar ayuda, sin importar demasiado su credo religioso.

La exposición sobre el primer mandamiento se completa con el rechazo de ciertas prácticas (creencia en sortilegios, mal de ojo, días nefastos, cantos de los pájaros,..) que se van a ver reforzadas con una serie de alusiones a otra clase de prácticas que contradicen la virtud de la fe, cuando habla de las virtudes teologales, ya que en ambos lugares, el planteamiento de fondo es común.

* $2^{\circ}$ Mandamiento

Juan de la Marca recoge en una serie de afirmaciones algunas formas de quebrantar el mandamiento al manifestarse violenta o agresivamente contra Dios: "Dio non porra far questo" (línea 265); "Dio non ay fato bene questo" (línea 266); "Dio, per che ma fatto questo" (línea 266); "Dio, fame el pro que poi" (línea 267): ni siquiera admite la posibilidad de la duda o de la desesperación ante un hecho de graves consecuencias y que es capaz de 
hacer perder -aunque sea momentáneamente- la seguridad de la fe. El simple hecho de pronunciar alguna de estas frases ya es ocasión de pecado.

La misma falta de matización se percibe en la pregunta final: "Se iure sopra la cruce..." (línea 270-271), puesto que la moral ha señalado que en determinadas condiciones es bueno efectuar un juramento, extremo que parece excluido de la perspectiva del autor de la Confessio.

* $3^{\circ}$ Mandamiento

En la pregunta "Se sey andato a la messa et ay venduto o comperato salvo in casu de necesita" (líneas 275-276) se encuentra el único ejemplo de matización, que suaviza la rotundidad de los juicios de la Confessio, puesto que se considera malo comprar o vender en el trayecto hacia la misa (se supone que en domingo o día festivo), con la salvedad de que puede haber situaciones de necesidad que lo justifiquen.

* $4^{\circ}$ Mandamiento

El cuarto mandamiento también recuerda la formulación del precepto al comienzo de la exposición. Esta se centra, preferentemente en el comportamiento hacia los padres, con lo que se podría entender como una excepción al hablar de "se hay fatti scandalizar" (línea-283), que por principio supone la influencia negativa del superior hacia el inferior, induciendo a pecado; en este caso de los padres hacia los hijos, y no a la inversa, como están redactadas el resto de las preguntas que versan sobre el comportamiento de los hijos hacia sus padres.

* $5^{\circ}$ Mandamiento

También en esta ocasión la Confessio empieza proponiendo la fórmula del mandamiento. Las posibilidades de pecados que la Confessio contempla entran dentro de lo normal, sin que destaque ninguna en particular a excepción de la que incluye la negativa al perdón: "Se ay desiderata la destrutione del tuo inimico et non voli perdonare" (línea 289-290), que recuerda las enseñanzas de Jesús no sólo respecto a los actos externos, sino también a las intenciones (Mt. 5,43-47).

* $6^{\circ}$ Mandamiento

Al abordarlo, recuerda su enunciado, pero no vuelve a repetir lo que ha tratado con ocasión de la lujuria, remitiendo a este lugar.

* $7^{\circ}$ Mandamiento

Tras el enunciado del precepto, la Confessio contempla algunos de los supuestos que lo quebrantan. La enumeración no es exhaustiva, y en este 
caso -como ha hecho en el $6^{\circ}$ mandamiento- no remite a la consideración de lo que ha dicho anteriormente con respecto a la avaricia, como podría parecer lógico.

Lo que llama la atención a la sensibilidad actual es el hecho de que sitúe a la mujer en la categoría de bienes muebles en el mismo plano de igualdad que los animales, el dinero u otras cosas, aunque ciertamente las categorías del momento de la redacción no coincidiesen con las actuales.

* $8^{\circ}$ Mandamiento

Formula el mandamiento. A continuación propone una serie de posibilidades: engañar por medio de la palabra ("falso testimonio"), o por medio de los hechos, defraudando ("Se ay falsificato el segelo, ...letera,... carta, ...moneta, peso o vero mensura, o vero mercancia posta al umedo..."). En este segundo caso, bien podría haberlo situado en el contexto del robo, y por consiguiente haberlo propuesto en el $7^{\circ}$ mandamiento, pero Juan de la Marca ha preferido acentuar el aspecto de falta de verdad más que el de robo o perjuicio económico. Otro tanto sucede al preguntar: "Se ay iurato la mensogna maleciosamente" (línea 307), ya que al intervenir el juramento tendría que haberlo ubicado preferentemente en el $2^{\circ}$ mandamiento.

* $9^{\circ}$ y $10^{\circ}$ Mandamientos

Juan de la Marca se limita en este punto de la Confessio a repetir los enunciados de los respectivos mandamientos, sin ningún tipo de pregunta explícita de cara a la confesión, estimando que resulta suficiente con esto y no hay necesidad de incidir en más preguntas.

Al término del examen de conciencia a través de los mandamientos no queda más remedio que hacer una recapitulación obligada, ya que, salvo en los mandamientos $2^{\circ}$ y $3^{\circ}$, ha ido formulando cada uno de los preceptos. Contrastando esta formulación con la que aparece en las líneas 14-19 se aprecia que la expuesta en la Confessio se articula en diez mandatos, al considerar dos preceptos diversos para los bienes y la mujer del prójimo (los propone en este orden, y no en el usual orden inverso: mujer y bienes), en tanto que la enumeración de la línea 18, al no subdividir el último mandamiento, queda circunscrita a tan sólo nueve preceptos en lugar de los diez habituales. Ligera modificación en la cantidad, y ligera modificación en el orden.

\section{Sentidos corporales.}

Resulta chocante el empleo reiterado de la palabra "sentimento" en lugar de la palabra "senso", pero ya ha habido oportunidad de comprobar la calidad del italiano empleado. 
En las líneas 79-80 (Compendium) se había limitado a hacer la simple enumeración de los sentidos. Ahora, desde la óptica sacramental, contempla la posibilidad de pecar que cada uno de ellos conlleva. La vista puede ser ocasión de amenazas ("menaciando con l'ochie", línea 317) o de miradas lujuriosas ("se ay guardato ad alcuna persona voluntieri ad le cose desoneste et vane", línea 318). El oído puede ser aplicado a la murmuración ("se ay inteso voluntieri murmuratione", línea 321 ), o a los sonidos vanos ("...o soni vani", línea 323). Por el gusto se puede pecar principalmente en la línea de la gula (líneas 325-326); pero como el gusto se localiza en la boca, y principalmente en la lengua, asocia a ésta las palabras inútiles ("multe parole occiose per far ridere", línea 327). Resulta complicado encontrar pecados que puedan atribuirse al sentido del olfato, pero Juan de la Marca señala dos en la línea de apetecer algún olor, o también en el hecho de aplicarse alguna substancia olorosa para difundirlo; parece que el pecado tendría que ser más de soberbia que de falta por el olfato. Finalmente, respecto al tacto señala algunos posibles pecados que bien podrían haber sido ubicados en la lujuria. También en el caso del tacto procede recordar que vuelve a hacer la consideración moral de pecado grave ("ay peccato mortalmente", línea 334), como una de las ocasiones en que desciende a semejante detalle.

El hecho de que el apartado de los sentidos corporales resulte relativamente común en los catecismos obliga a otorgarle un trato paritario con vistas a la penitencia.

\section{Artículos de la fe.}

Este apartado constituye la excepción en la Confessio, pues abandonando el propósito de preparación para la recepción del sacramento de la penitencia, Juan de la Marca se decide por el estilo catequético expositivo presentando la síntesis de la fe según los dictados del símbolo apostólico. La división del símbolo en los doce artículos responde exactamente a la que había presentado el Compendium (líneas 4-14), con dos diferencias: en la primera presentación iba atribuyendo a cada uno de los apóstoles la frase correspondiente, cosa que no hace en esta ocasión; y mientras la primera redacción en el Compendium estaba en latín, la segunda de la Confessio consta en italiano. Pese a lo cual subsiste en ambas la expresión irregular de "Pillato" (línea 8, para el Compendium; línea 339, para la Confessio, con la particularidad, en este último caso de haber eliminado el nombre de "Poncio").

\section{Sacramentos.}

El apartado de los sacramentos vuelve a retomar el estilo de confesional para volver a incidir en las preguntas que pueden suponer conductas pecaminosas con relación a ellos. 
Llama la atención el hecho de que además de enumerados y acompañados de las preguntas correspondientes, los sacramentos se encuentren resumidos de nuevo al final del apartado, en una simple enumeración en latín (líneas 354-356). Y sorprende más aún el hecho de que tanto en la primera de las dos exposiciones (con preguntas), como en la segunda (sin preguntas) se observe un extrañísimo orden ya que ponen el matrimonio en tercer lugar y la unción de enfermos en cuarto lugar, cosa absolutamente insólita y totalmente fuera de la habitual presentación de los sacramentos. No se observa este orden en la presentación llevada a cabo en el Compendium (líneas 4445) que se ajusta a la formulación tradicional. De ahí la extrañeza que produce, por partida doble, la ordenación de los sacramentos que aquí encontramos.

Respecto al bautismo, la pregunta complementaria indaga sobre la omisión culpable que se haya podido hacer del mismo. La confirmación ni siquiera viene acompañada de pregunta alguna. El matrimonio va acompañado de dos preguntas, una sobre el uso del matrimonio y otra acerca de la abstención del mismo en los tiempos prohibidos, por su caracter sagrado, que impedían la normal utilización de la vida sexual.

En relación a la unción de enfermos, la pregunta que lo acompaña ("Se sey stato unto nel tempo dela morte", línea 350-351) carece de la más absoluta lógica, puesto que, como el nombre y la práctica señalaban, se trataba de la unción a los que estaban abocados a la agonía; de aquí que carezca de sentido hacer una pregunta así, excepto en el caso de quien ha rechazado formal y culpablemente la unción y además ha sobrevivido a la enfermedad o al peligro.

La pregunta que está vinculada a la confesión ("Se sey stato confesato a lo meno una volta al anno", línea 352) conecta con los mandamientos de la Iglesia (líneas 39-41), que no aparecen en la Confessio expresamente.

A propósito de la eucaristía, hay que advertir que el texto no designa expresamente el sacramento con su nombre, sino que se limita a señalar la obligación que existe de recibir el cuerpo del Señor una vez al año, con lo cual conecta con lo formulado en el apartado de los mandamientos de la Iglesia (líneas 41-44), donde, por cierto, lo hace introduciendo más matices que en la enunciación aquí empleada. El sacramento del orden viene acompañado con un extraño adjetivo "crelicale" (línea 353), que, sin embargo, aparece correctamente escrito -si bien en latín- en la línea 356, como si el hecho de escribirlo en italiano se prestara a una confusión difícil de explicar. Tan extraña como el aludido adjetivo, es la pregunta que se adjunta al sacramento, pues interroga: "se ay observato l'ordine diligentemente" (línea 354), cuyo sentido exacto resulta difícil de precisar: no se adivina bien si lo que 
pretende averiguar es si el ordenado ha recibido el sacramento en debidas condiciones; o si el no ordenado ha respetado suficientemente al que está ordenado.

\section{Obras de misericordia corporales.}

Cuando en el Compendium aparecían las obras de misericordia (líneas 22-30), el orden seguido era presentar primero las espirituales y después las corporales; aquí se opta por el orden inverso. Otra diferencia estriba en que la enunciación del Compendium es más concisa. Y en tercer lugar, en ambos casos no se siguen idéntico orden entre la lista de las corporales o de las espirituales.

Concretamente, en lo que se refiere a las obras de misericordia corporales, en la segunda de ellas, omite el enunciado (Dar de beber al sediento), para centrarse únicamente en la transgresión u omisión correspondiente. Exactamente a la inversa procede con ocasión de la séptima, de la que pone el enunciado, omitiendo en este caso la posibilidad de preguntar por la omisión de tal acción.

Para poder suplir la omisión de la sexta obra de misericordia, lo que hace el amanuense es forzar la introducción de una línea al final de la página, con lo que rompe el sentido de lo que había escrito previamente, pues salvando dicha línea postrera el sentido de la redacción era: “... se sey stato negligente ad vestir el nudo povere...".

La última anotación es la de hacer caer en la cuenta que las preguntas que pone como posibles trangresiones de las exigencias de caridad inherentes a las obras de misericordia suelen limitarse a la pura y simple repetición casi literal de los enunciados de cada una de ellas.

\section{Obras de misericordia espirituales.}

Tampoco en este caso sigue el mismo orden que figuraba en el Compendium (líneas 23-27). Repite, como en el caso de las obras de misericordia corporales, una serie de preguntas que reproducen el enunciado y que únicamente indagan si se ha sido diligente o negligente a la hora del cumplimiento de las mismas. Con todo, no deja de ser curioso el matiz que introduce en la quinta obra de misericordia espiritual, en cuyo enunciado figura "Pregar per li pecaturi" (línea 372), y en cuya pregunta complementaria añade: "pregar dio per tutti le peccaturi et per la ecclesia" (línea 373). 


\section{Virtudes teológicas.}

Ya ha habido ocasión de comprobar que en el Compendium (línea 67) las llamaba "virtutes theologice"; ahora, con una nueva inexactitud, las denomina: "le virtute theoliche" (línea 377).

Las enumera sucintamente, y se limita a preguntar si ha tenido auténtica fe y esperanza en Dios (línea 378). A continuación, las preguntas de la Confessio se orientan a averiguar una serie de posibles prácticas de índole supersticiosa: realizar encantamiento o pócimas en un recipiente, acudir a por determinadas hierbas el día de San Juan ${ }^{48}$, hacer predicciones ("fare fatura"); consultar al demonio, practicar la nigromancia, invocar a los astros... Todo ello son formas de contravenir las exigencias de la fe, más las de la ciperanza o de la caridad que sigue enumerando. También en este grupo de las transgresiones respecto a los pecados contra las virtudes teológicas aparece por tercera vez la calificación expresa de pecado mortal: "Se ya fata alcuna incantatula in polla.... ay peccato mortalmente", (líneas 380382), transformando la pregunta en una afirmación.

\section{Dones del Espíritu Santo.}

Las preguntas del confesional a este respecto más bien parece que son una especie de preguntas agrupadas en torno a un último apartado sin demasiado orden, pues empieza preguntando por la esperanza (línea 391), de la que había hablado en las líneas 385 y 388. También pregunta por la puesta en práctica de la piedad (línea 391), por la fortaleza ante la tentación (línea 392), y por la buenos consejos dados (línea 393), que aluden a algunos de los dones del Espíritu Santo. Pero en el interrogatorio se hace caso omiso de los otros, simplemente como si no existieran. En el Compendium (líneas 55-61) al menos los enumera todos (aunque sea oponiéndolos a los pecados capitales), pero en la Confesssio ni siquiera todos aparecen; y los que lo hacen ni siquiera en la forma expresa del enunciado, sino en la más velada de enumerar algunos posibles pecados.

\section{Circunstancias del pecado.}

El último apartado de la Confessio -y del Catecismo- es el dedicado a rematar la cuestión de una buena confesión con la especificación por parte del penitente de las circunstancias que rodean cada pecado, y que entrañan

48. Recordemos nuestra canción tradicional: “A cortar el trébole la noche de San Juan", noche mágica y con ignotas connotaciones que se pierden en la noche de los tiempos. 
una especial gravedad. Las circunstancias que la Confessio contempla son las de tener en cuenta las personas, el número de pecados, el lugar, la ayuda de que se dispuso, la reiteración, el modo (la circunstancia podría ser aplicada a cualquier índole de pecado, pero es claro que al menos al hablar del modo, el autor está pensando en pecados de índole sexual), el día, y la publicidad que se ha dado al pecado en cuestión.

A este respecto, la Confessio resulta más meticulosa en el examen propuesto, que el que lleva a cabo el apunte de confesional que aparece en el catecismo de Pedro de Cuéllar, el cual interroga únicamente por tres tipos de circunstancias: la persona, el lugar y el tiempo (PC 21v). Pero ya vimos que el confesional del catecismo de Pedro de Cuéllar no resulta, en conjunto, tan completo ni tan sistemático como el que aquí se presenta, de manera que nada tiene de particular que en el recorrido por las posibles circunstancias, existan diferencias entre uno y otro.

Con la inclusión de un "Deo gratias" final (línea 403) termina el confesional. Hemos podido ir viendo su estilo en que va progresivamente interrogando al penitente acerca de una serie de posibilidades de cometer trasgresiones contra la voluntad de Dios, o contra la disciplina de la Iglesia. El interrogatorio resulta ciertamente bastante completo; no se puede decir que sea totalmente exhaustivo, pero sí hay que reconocer que va dejando pocos resquicios a la libre interpretación personal de las obligaciones del cristiano, puesto que están perfectamente reglamentadas y se trata de que el sacerdote tenga en sus manos un adecuado instrumento que permita conocer en cada caso la situación exacta de la conciencia, que sirva, a la vez, para que el penitente lleve a cabo una confesión íntegra, sopesadas todas las posibilidades. Sus 346 preguntas, además de las preguntas implícitamente presentes, pero no formuladas de una manera expresa (por ejemplo, en el caso del noveno mandamiento) hacen un completo recorrido por las cuestiones en que el cristiano tiene que dar cuenta a Dios de sus actos pidiendo perdón de ellos.

Indirectamente, como ocurre con todos los confesionales, resulta un elocuente y fidedigno instrumento para conocer el pensamiento y costumbres de los cristianos de aquella época medieval, los acentos que se ponen en su conducta, las omisiones que se echan en falta, lo que constituyen costumbres de tipo popular, las prácticas sancionadas como rechazables, los hábitos alimenticios y económicos, los defectos más comunes, la sensibilidad social, la plasmación práctica de su religiosidad... En definitiva, es un retrato de una sociedad cristiana concreta; retrato que -en términos fotográficos- es necesario positivar, puesto que la lógica interna del confesional es la de indagar sobre los defectos y omisiones; en consecuencia hay que invertir el sentido de las preguntas para conocer lo que estaba sancionado como bueno y que 
hacía a quien lo practicaba merecedor de un premio. Se pueden comprobar que junto a comportamientos inalterables y básicos en el cristianismo, se encuentran otros ligados a la temporalidad de las costumbres del momento, y que han perdido sentido o actualidad desde la óptica de la moral actual. Pero así es la Iglesia de Cristo: no una comunidad inasequible a las circunstancias temporales, sino un grupo de creyentes inserto en el tiempo, hijo de su época, y que busca en el aquí y el ahora la fidelidad a su Fundador.

Esa comunidad ha formulado la vieja e inalterable fe cristiana en lo que fueron, en los siglos XIV y XV, odres nuevos; pero que ahora se nos antojan odres viejos. Podemos contemplar los odres como lo que son: envoltura, continente. Y saboreemos el vino añejo de la fe que nos han transmitido, constituyéndose en un eslabón de la secular e ininterrumpida tradición eclesial. 


\section{TEXTO DEL CATECISMO MEDIEVAL LATINO-ITALIANO}

\section{[141r] INCIPIT COMPENDIUM DE DOCTRINA CHRISTIANA}

Quilibet christianus debet primo scire pater noster ut possit orare. Deinde debet bene adiscere credo in deum et imo bene notare quod in eodem continentur XII articuli fidei secundum numerum XIIm apostolorum. Petrus:

5 Credo in deum patrem omnipotentem creatorem celi et terre. Andreas: Et in ihesum christum filium eius unicum dominum nostrum. Jacobus: Qui conceptus est de spiritu sancto, natus ex maria virgine. Johanes: Passus sub poncio pillato, crucifixus, mortus et sepultus. Thomas: Descendit ad inferos, tercia die ressurrexit a mortuis. Jacobus minor: Ascendit ad celos, sedet ad

10 dexteram dei patris omnipotentis. Phillipus: Inde venturus est iudicare vivos et mor et mortuos (sic). Bartholomeus: Credo in spiritum sanctum. Matheus: Sanctam eclesiam catholicam. Simon:/[141v] Sanctorum communionem, remissionem peccatorum. Thadeus: Carnis ressurrecionem. Mathias: Vitam heternam. Amen.

15 Post hec discat precepta. Non adorabis deos alienos. Non asumes nomen dei tui in vanum. Memento ut diem sabati sanctifices. Honora patrem tuum et matrem tuam. Non occides. Non furtum facies. Non mechaberis. Non falsum testimonium dices. Non concupisces res proximi tui. Unde versus: Unum cole deum, nec iures vana per ipsum ${ }^{49}$. Sabata sanctifices. Habeas in

20 honorem parentes. Non sis occisor, fur, ...ctus ${ }^{50}$ testis iniquus. Uxorem alterius. Nec cupies rem alienam.

Precepta evangelii sunt duo ${ }^{51}$ quae distinguntur in opera misericordie. Septem spiritualia et septem corporalia. Spiritualia sunt hec, scilicet: Docere ignorantem. Dare consilium herrantem. Corrigere derelinquentem. Conso-

25 lari tristem. Remittere iniurias. Substinere personas graves. Orare pro omnibus, scilicet, amicis et inimicis. Unde versus: Consule, castiga, solare, remitte, fer, ora. Corporalia sunt ista, videlicet: Visitare infirmos. Cibare esurientes. Potare sicientes. Vestire nudos. Redimere cautivos. Sepelire mortuos. Hospitare peregrinos. Unde versus: Visito, poto, cibo, reddimo,

30 tego, colligo, condo.

Ista sunt quinque precepta ecclesie, videlicet: Quilibet christianus tenetur adiscere pater noster. Et credo in deum. Et patres. et matres spirituales

49. El sentido de la versificación pediría: nec iures vana per eum, como hace un catecismo hispano-latino medieval.

50. Palabra ilegible, tachada en el original. Por el sentido, y por la comparación con otros textos, debe ser "mechus".

51. Resuena el eco de Mt. 22,36-39, pero en lugar de seguir presentando el compendio de la ley, el texto deriva hacia las obras de misericordia. 
debent de hiis docere filios suos spirituales, cum ad hetatem legitimam pervenerint. Quilibet christianus custodiat se ab operibus servilibus et rebus

35 illicitis, et missam integram audiat diebus dominicis et festis in sanctis constitutis. Nemo, tamen, ad impossibile tenetur./ [142r] Quilibet christianus supra XXI annos et infra LXX tenetur si non habet legitimum impedimentum iegunare totam quatragessimam, et quator tempora, et omnes vigilias sanctorum institutas ad ieiunandum. Quilibet christianus posquam ad annos

40 distincionis pervenerit, videlicet, masculus ad XXIIII, femina vero ad XII, tenetur omni anno semel confiteri omnia pecata sua. Quilibet christianus tenetur semel in anno accipere corpus sanctissimum christi in prima die ressurrecionis domini nostri ihesu christi, nisi confessor suus discretus propter causam legitimam ei aliter consuleret. Et hoc posquam ad anos distincionis

45 pervenerit. Et hoc quidem, magis cito, vel minus cito, secundum rationem et ignorantiam actingatur annos distincionis tam masculus quam femina ut supra scriptum est.

Ista sunt VIIem sacramenta ecclesiae, videlicet: Bautisma. Confirmatio. Penitentia. Eucharistia. Extrema untio. Ordo. Matrimonium. Quorum tria 50 tantum sunt nescesaria cuilibet, scilicet: Bautisma. Penitentia. Et eucharistia. Alia, autem, particularia sunt ad bene esse, videlicet, in universali bene sunt nescesaria. Etiam ordo et matrimonium, quia in ecclesia oportet esse clericos, sive sacerdotem et coniugatos.

Ista sunt VII ${ }^{\mathrm{em}}$ dona spiritus sancti.

55 Timor domini — et hoc spellit Superbiam

Pietas - et hoc spellit Invidiam

Donum sciencie —- et hoc spellit Iram que est quedam stultitia

Fortitudo et hoc spellit Accidiam

Consilium — et hoc spellit Avaritiam

60 Intelectum et hoc spellit Gullam

Sapientia et hoc spellit Luxuriam.

I[s]te sunt quatuor virtutes Cardinales, videlicet:/[142v]

Providencia - qua homo nichil ap[petit]

Temperancia — qua homo nichil appetit, unde fit penitens

65 Fortitudo - quae est firmitas contra adversa

Iustitia $\longrightarrow$ que est virtus sua unicuique reddere.

Iste sunt virtutes theologice, scilicet:

Fides

Spes

70 Caritas

que secundum apostolum maior horum est ipsa caritas $^{52}$

52. Hace referencia a 1 Cor 13,13 . 
Ista sunt septem vitia capitalia, videlicet:

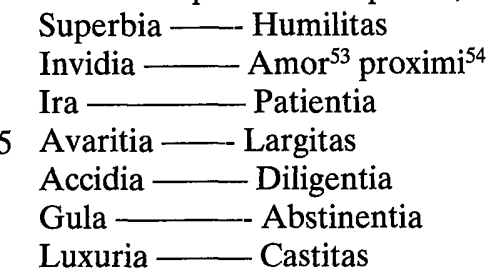

Quinque sensus corporis:

80 Bisus, Auditus, Gustus, Odoratus, Tactus.

Isti sunt tres potentie anime.

Memoria, Intelectus et Voluntas.

Ista sunt indumenta spiritualia ac anime, videlicet:

Innocentia, Matrimonialis castitas. Spiritualis matrimonium anime est

85 nomen dei (secundum quod dictum in evangelio): non ex solo pane vivit homo ${ }^{55}$.

Ista sunt IIIIor consilia ihesu ćhristi ad quae tenentur viri perfecti:

Mansuetudo et profunda humilitas ut in evangelio: si quis te percusserit in una maxila, prebe ei alteram ${ }^{56}$. Paupertas spiritu ut in evangelio: si vis per-

90 fectus vade et vende omnia quae habes ${ }^{57} . /[143 \mathrm{r}-145 \mathrm{r}=$ calendario $] /[145 \mathrm{v}]$

[Orationes]

O domine iesu christe, adoro te in cruce pendentem, coronam spineam in capite portantem, deprecor te ut tua crux liberet me a percutiente angelo.

O domine iesu christe, adoro te in cruce vulneratum, felle et aceto potatum, 95 deprecor te ut tua vulnera sint remedium anime mee. Amen.

O domine iesu christe, adoro te in sepulcro positum, aromatibusque conditum, deprecor te ut tua mors sit mea vita. Amen.

Quicumque dixerit has tres orationes cum quinque pater noster mundo corde ante figuram domini nostri iesu christi quando exivit de sepulcro

100 habet de indulgentia XX milia annorum et ultra concessa a beato gregorio et a multis aliis eius susscesoribus ut patet in urbe rome clarius in conventu./

53. Hay una "o" tachada en el original.

54. Hay una "i" tachada en el original, que dice "proximii".

55. Mt. 4,4. El texto de la Vulgata, sin embargo, dice: "Non in solo pane vivit homo".

56. Mt. 5, 39.Se aproxima al texto de la Vulgata, que dice: "Si quis te percusserit in dexteram maxillam tuam, prebe illi et alteram"

57. Mt. 19,21, que se aproxima al texto de la Vulgata: "Si vis perfectus esse, vade, vende quae habes...". En cambio no cita Mt. 5,3 al hablar de la pobreza de espíritu. 


\begin{abstract}
Absolutio
Dominus iesus christus ipse te absolvat et ego te absolvo autoritate qua fungor. Et iterum te absolvo ab omni vinculo excomunicationis. Et restituo

105 te in VIIem sacramentis eclesie. Et iterum te absolvo ab omnibus peccatis tuis michi confessis et oblitis et omnia bona que fecisti sint ad laudem dei in remissionem peccatorum tuorum. Amen. Dic pater noster, fac penitentiam, vade in pace et amplius nolli peccare. In nomine patris et filii et spiritus sancti. Amen./ [146r]/
\end{abstract}

110 Confessio devotissima fratris iohanis de marchia.

A devocione de ciascheduna persona et deli devoti peccatori me so igneniato de far aquesta regula acio che l'animo de aquelorum che la leierano se vengano ad salvare guardandose guardando se (sic) d'aquello che in questo libro se tratta. Et per questo hordine sapiano mello lo loro peccati confessa-

115 re. Ad cio che piu graciosamente l'altissimo dio li agia misericordia et perdonili li soi peccati. Et dequesto poneremo XII articuli et regule neccesarie ad la nostra confessione.

La prima regula si he quanto ad la sua preparacione. Et nonche sono XII li preparacioni. La prima si he quanto tempo si he che non te confesasti. La

120 seconda si he si tu ha fata la penitencia che te dio el sacerdote quando te confesasti. La tercia si he quanti peccati ai fatti depoi che te confesasti. La quarta si he quanti peccati ay conmessi conla compagnia. La quinta et la sexta, si he in quanti luochi ai fati li peccati. La septima si he se ai peccato nel'arte toa. La ottava si he si ay peccato in alcuno officio che ay avuto. $\mathrm{La}$

125 nona si he quanti pecati ai comessi inanti el matrimonio. La decima si he fa che trove diligentemente el buono confessore et che aya la autorita. La undecima he che dui di enanti che te confessi examina molto bene la constientia dele cose supraditte. La XII ${ }^{\mathrm{a}}$ si he que quando te vole confessare vade composito de confessar tutti li toi peccati et de satisffare, et de astiner-

130 tene per lo avenire quanto dio ti dara la grazia et forteze.

Sequitano de li VII peccati mortali.

De superbia

Se ay despreçata alcuna persona. Se te sei vantato di quello che non ay fato. Se te sey reputato mello de altrui. Se ay tenuta la toa oppinione contra la

135 veritade. Se ay voluto esere laudato dela virtude che tu ay. Se ay avuta superbia/[146v] di capelli belli o belli panni che abi avuto per parentato, o de beleze. Se te sei vanagloriato en famellia, o vero en riqueza. Se te sei reputato de sapere aquello che non sai. Se ay voluto esere servuto et non servir, esere honorato et non honorar altrui. Se ay laudato la opera tua et

140 la daltrui biasmata. Se non ay voluto esere represo. Si piu ha creso ad te medesimo che ad altri homini piu santi de te. Se ay fata iniuria ad altruy. Se ay dispreçata l'opera virtuosa. Se ay defeso la male che ay dicto. Se te piaçuto laudar li captivi. Se ay sequitata la mala compagnia. Se ay voluto intendere li cativi piu presto che li bueni. Se te sey vergognato deli parenti 145 poveri. Se ay fata iniuria iniustamente. Se ay fato contra la salute del'anima 
tua. Se ay fato vergognia a le povere persone. Se ay fatto maritamento ad li toi amici in casa toa. Se ay retenuta la possessione de altri iniustamente ${ }^{58}$.

\section{De invidia}

Se ay avuta tristicia del beni de altrui, o vero malanconia. Se te sei alegrato 150 del mal d'altrui. Se ay dapnificato al amo per invidia. Si porte addio ad alcuno con lo core et con la mente. Se ay offeso el tuo amico. Se ay invidia ad altri de fillioli o de possessione. Se ay [in]vidia de honore o dignitate et laude quando altre he amato assai del suo signore.

De ira

$155 \mathrm{Si}$ porte rancore ad visugno. Se impatientemente te turbi contra dio et listi cola famillia de casa, o vero altre persone. Se vetuperi alcuno in parole o in fati. Si feristi o guastasti membro ad alcuna persona. Se demosti ad alcuno mala cera. Se sey impaciente quando no trovi aparechiato ad tuo seno quelo che voli. Se menaci a lo proximo ad alta voce./ [147r] Se con ira mani-

160 festasti cosa secreta. Se iurasti de non far piu bene. Se per ira ai turbata la compagnia o la ca[sa]. Se per ira dixisti: yo non te regratio, ma te degratio. Se per ira lasasti lo bene fare. Se te adire quando quelle che te chiedono denari che degono avere rasionivelemente. Si per ira ay dito ad alcuno: guardate da me, che te faro et te diro, Se per scriptura ay offeso ad alcuno.

165 Se ay infamiata alcuna persona. Se cacciasti may alcuno de casa. Se per ira consigli [mal $]^{59}$ ad alcuno che facia male. Se fai alcuna cosa con furia. Se te conturbi quando no te fato honore. Se te adire per le cose perdute. Si iure sempre de dir male.

\section{De accidia}

170 Se te infastidio li diiuni, e li conmandamenti, et lo ascoltar dele mese et dele prediche. Se non ay fede de perseverar in bene. Si lassi lo bono conmençamento per negligentia. Se ay la mente $\operatorname{con}^{60}$ le cose desoneste. Se fay lo servicio con accidia. Se stai accidiuso quando intendi aquello che non te piace. Se sey de poco animo ad far bene. Se sei negligente ad far la peniten-

175 cia. Se sei negligente ad far confesar et communicar la toa famiglia. Se sey negligente ad satifar li testamenti quando sei fidecommissario. Se lase morire alcuno sensa confessione. Se sey negligente ad visitar le infirmi et li poveri. Se per tua [o]casione ${ }^{61}$ se perdeno li boni temporali. Se per tua negligencia ai dati cativi consilli. Se sei stato occioso nela vanita del mundo.

180 Se sei stato negligente ad trovar el buon confessor. Se sei stato negligente a

58. Tachado está escrito: "iniustatmente".

59. Está tachado, pues repite en la misma frase "male".

60. La palabra aparece en contracción que podría interpretarse como "contra", pero el sentido de la frase requiere que se interprete como "con": tener la mente ocupada con (o en) cosas deshonestas.

61. En el texto figura claramente como "casione", tanto en ésta como en las otras oportunidades en que aparece esta palabra. 
trovare et examinare la toa consciencia. Se ay pregato dio che te facia la vendeta. Se per toa negligencia sei in alcuno scandalo.

De avaricia

Se ay fatta mai luxuria. Se ay tenuti pegni et sfrutate ti li. Se ay prestata

185 pecunia et ayne avuto altro fructo./ [147v] Se ay venduto ad termini alcuna cosa. Se ay comperati li fruti el tempo, cio e, nanti che siano recolti, cio e, per aver megloro mercato. Se ay data la casa vechia per aver la nova et non ay fato per servir el proximo. Se ay prestato ad alcuno denari che te facia la usura. Se per prestare denari ad altri ne ay demandati [denari] ${ }^{62}$ servicii o

190 doni. Se ay dato ad guardar le bestie et vole che lo guardiano satisfacia quele que fosero morte per iudicio de dio et non per mala guardia. Se ay posedute dote, o vero possessione de altri. Se ay retenuto salario a li toy lavoratori ${ }^{63}$. Se ay messo fuoco in casa, $o$ in villa, o in castello, o vero in terra. Se ay comperate cose robate. Se ay trovate cosa d'altre et non l'ay

195 rendute a lo proxime. Se ay fato dapno ad alcuno et non ay fato l'amena. Se cavalcando ay guasti biade daltrui. Se ay dato piu presto lo pane al cane che al povero ${ }^{64}$. Se sei stato avaro nel dar delle limosine. Se ay tenuta la cosa che te e stata prestata. Se ay dapnificato alcuno con opere o con parole. Se ay comandato a le toi subditi cha faciano male. Se ay permesso che alcuno

200 facia male ad altri. Se sei stato negligente a la ragione de core. Se sey stato adiutore de capture deli infideli contra li christiani, o vero ce ay consentuto. Se ay retenuta la rasione ad altrui. Se ay retenuta carta o testamento in periudicio de altri. Se ay mutati li termini de li terre ${ }^{65}$. Se sei stato arbitro et ay dato mala sentencia. Se ay stato comperatore de bo[n] ${ }^{66}$ daltri, o vero

205 dela ecclesia et non ay restituito integramente. Se hay posseduto la casa daltrui et poi la ay data ad altri. Se ay posseduto le cosi de li morti et non l'ay satisfato secondo el testamento. Se ay despeso le cose de altrui in tua utilita./ [148r] Se ay dapnificato alcuno in preparacione, o vero in advocacione, o vero in scriptura, o vero in falsa testimonia, o vero in acusatione. Si

210 con minacie ay dapnificato alcuno. Se ay impedito il guadagno de altri. Se ay impedito che non se rendra la roba daltri ${ }^{67}$. Se ay dato adiutorio in dapno daltri. Se ay adconsentito a lo dapno de altrui.

De gula

Se ay lasati li deiunii comandati. Se ay magnato caso o latte quando ay 215 deiunato. Se si stato inbriaco, o vero imbriagato de altri. Si per superchio magnar a vomagato. Se ay magnato cose finate, o vero de malo aquisto. Se ay magnato, o vero beuto sensa necessitate. Se sei stato turbato quando non ay trovato da magnar. Se sey seduto tropo a la mensa. Se ay magnato

62. Aparece, tachada, la palabra "denari”, que había copiado antes.

63. Se hace eco de Lv. 19,13, así como de St. 5,4.

64. Resuena el relato evangélico del pobre Lázaro: Lc. 16,21.

65. Resuenan Dt. 19,14 y Dt. 27,17.

66. Literalmente, "boi", pero el sentido reclama reconstruirla como "boni".

67. Resuena el eco de Dt. 24, 12-13. 
nanti che ay odito la messa la domenica. Se per magnar superchio te si infir-

220 mato. Se per tropo magnar o bevere ay lasato la oracione. Se ay dormito superchio. Se ay conversato con le persone desoneste. Se non ay deiunato nanti che te comunique. Se per tre di nanti et tre di dapoi che te si comunicato non te si abstenuto del matrimonio. Se ay magnate cose da iudei. Se ay magnato curiosamente.

De luxuria

Se ay peccato nel vicio dela sodomia, cio e, maschio con maschio, et femina con femina. Se ay peccato con li animali. Se ay peccato contra natura, contra te medesimo. Se ay peccato contra li parenti. Se ay peccato con la matre, et con la monica in loco sacro, o vero con virgine, o vero con marita-

230 ta, o vero con pagane, o iudey, o vero meretrice publica, o vero con la conmare. Se con la mente ay desiderate le sopraditte $\cos ^{68}$. Se ay acompagnato altruy/ [148v] a lo vicio dela luxuria. Se ay may sforçata nisuna per luxuria. Se ay may conmeso nisuna desonesta nel matrimonio con la toa donna. Se ay magnato [meglo $]^{69}$ tropo per meglo luxuriar. Se ay fato alcune

235 confecione, o cose calde per meglo luxuriar. Se per veder l'ammor sey an[d]ato ala chesia, o vero messa ad udir predica, o vero ala confessione ay pecato mortalmente. Se con la mente ay fato omiccidio, o vero questione. Se ay fato qualquier cosa a cio che la dona gravida non partorisca. Se una dona maritata. Se una dona maritata (sic) da uno figlo aut una figla non

240 legitima comite addulterio. Se ay pillato una jovena per mogle contra la volunta del compadre, o dela iovena. Se ay nante che mora la propia mogle ne pigla un altra. Se ay piglato mogle nel modo prohibito dela santa romana ecclesia. Se ay impedito el matrimonio. Se ay dato ad magnar alcuna cosa cativa a la femina che te voglia bene et facia el tuo volere. Se ay inseg-

245 nato ad alcuna persona le cose desoneste et brute. Se ay fato cantare, sonare, ballare, per [o]casione de luxuria. Se ay contrafata la toa facia con aconcime de cerosso $\mathrm{s}^{70}$ o vero altre cose. Se ay dite parole occiose per incitar ad luxuriar et dar malo exemplo ad altri.

Sequitano li X commandamenti dela lege.

250 In prima non aver per tuo dio altro che me. Se ay adorato altro che uno dio. Se on credi ala santa madre ecclesia circa vera(? $)^{71}$ et tutte le cose conminate per episcopum. Se dubite in alcuno articulo dela fede. Se tu dubite che non sia altro mondo. Se dubite che l'anima non mora may. Se ay dato consiglo, adiutorio, o favore a iudei, o vero infideli, o si laudi lo creator loro. Se

255 poi defendere lo /[149r]christiano contra li iudeo et infideli et non defendi. Se crede a li incanti, et a la sorte et a le signi. Se credi per scontrar alcuno

68. Recuerda implícitamente a Mt. 5,27-28. frase.

69. Figura tachado, como error del copista, pues aparece inmediatamente después en la

70. La expresión "aconcime de cerosso" tiene el sentido de ocultar una parte del cuerpo con la intención maliciosa de parecer hermoso, procovando con ello a la lujuria.

71. Lectura dudosa. 
sequire bene o male, dicendo: el tale me ha male ochiato. Se credi che lo bene o lo male que l'omo ha in questo mundo si sia destinato et non possa far altro. Se credi neli di ethiachi ${ }^{72}$, cio e, quello che $\mathrm{fa}^{73}$ en quello di, o ora

260 sia captivo, o vero b[e]ne no conmenstar alcuna cosa. Se credi neli canti de li osceli che signifique male, o bene. Se credi quando disce alcuno che nasce nela tal hora aver bene o male. Se credi a li domini $(. . .)^{74}$

Lo secundo commandamento

Se ay nominato el nome de dio in vano. Se ay biastimato dio, o vero li santi.

265 Se ay iurato per lo nome loro in vano. Se ay ditto: dio non porra far questo. Se ay ditto: dio non ay fato bene questo. Se ay ditto: dio per che ma fatto questo. Se ay ditto: dio, fame il pro que poi. Se ay iurato may per la fede, o per l'evangella, o per la [fede $]^{75}$ anima mia, o vero in buona constientia, o vero per bona fe[de]. Se sei officiale et non castigui quelli che biastimiano

270 dio et le soy sancti. Se iure sopra la cruce, o sopra la altare, o vero sopra le reliquie.

I.o tercio commandamento dela lege

$S_{i}$ ay guardate le sante domenice. Se lavore la domenica o le feste commindate dela santa ecclesia. Se ay fato lavorar le toy infanti, o vero le toy

275 bestie. Se ay fato mercato, cio he, vendere o comperare. Se sey andato a la messa et ay venduto o comperato salvo in casu de necesita. Se ay balato, o fato balar nele di de $1 \mathrm{a}^{76}$ festa nela ecclesia o cimiterio, o vero loco santo. Se ay avuto alcuna pompa el di dela feste.

Lo quarto commandamento

280 Se he: honorar(e) el patre e la matre. Se l'ay ditto alcuna parola aspera. Se le sei stato inobediente et inreverente./[149v] Se non l'ai subvenuto nelo lorum necesitate. Se ai furato alcuna cosa al patre et a la matre sensa loro licencia. Se hay fatti scandalizar. Se non ay satisffato loro testamento. Se te sey fato beffe de loro ridendo. Se le ay may posto mano adoso sensa loro

285 volere. Se ay pensato alcuno male de loro in alcuno modo.

Lo quinto commandamento

Si e: non occidere. Se iniustamente ay ociso o fato occidere alcuno. Se ay dato consillo, ayuto o favore nela morte daltri. Se ay ociso o fatto occidere alcuno per denari. Se ay desiderata la destrutione del tuo inimico et non

290 voli perdonare. Se ay dato el veneno ad alcuno. Se ay occisa la nete(?) ${ }^{77}$ nel

72. La transcripción parece que no ofrece dudas: "ethiachi"; resulta dificil localizar esta expresión que, por el contexto, tiene que ser equivalente a dias aciagos, funestos, adversos,...

73. Literalmente aparece "fan", con la " $n$ " tachada.

74. El texto se interrumpe, dejando esta frase incompleta.

75. "Fede" aparece tachado, pues lo acaba de copiar en la frase anterior.

76. Aparece tachada una palabra, en abreviatura, que podría ser "ecclesia".

77. Lectura dudosa. 
ventre dela matre con alcuna medicina. Se ay data medicina che non ingravide la dona. Se ay feruto alcuno et essene morto.

Lo sexto commandamento

Non far fornicatione, del quale ne he ditto a pieno nel peccato dela luxuria,

295 el qual he nele septem peccati mortali.

Lo septimo commandamento

Si he: non furar. Se ay furato nela citade, o castello, o villa, o animali, pecunia, femina ${ }^{78}$, o vero altre cose, et se ay consentido altri. Se ay trovata alcuna cosa en la via et non l'ay renduta. Se ay receputo alcuno furone o latro.

300 Se ay furato niente nela ecclesia. Se ay comperata o venduta la roba de altri furata.

Lo octavo commandamento

Si he: non far falso testimonio. Se sei stato falso testimonio, o ay induto altri. Se ay recevuti alcuni testimonii. Se ay condepnato altri per falso testi-

305 monio. Se ay falsificato el segelo de altri, o letera, o con falsa carta, o vero moneta, peso, o vero mesura, o vero mercancia posta al umedo per che tarvenga $^{79}$ li peso. Se ay iura- $/$ [150r]to la mensogna maleciosamente. Si ay inganato alcuno dicendo: per la fede mia, che te daro aquesto, et poy non li ai observato. Se ay parlato dopiamente, cio e, ditto una cosa et fatto unal-

310 tra. Se ay alosengato alcuno facia qualque male.

Lo nono commandamento

Si e: non desiderar la cosa del proximo tuo, la possesione, o vero el fameglio, o el fante, o el bove, o el cavalo, o asino, o vero altra cosa.

Lo decimo commandamento

315 Si e: non desiderar la dona del proximo tuo, ne altra cosa.

Sequitano le chinque sentimenti del corpo

In prima de li viso. Se ay guardato ad alcuna persona menaciando con l'ochie. Se ay guardato ad alcuna persona voluntieri ad le cose desoneste et vane. Se ay fato alcuno segno con lo ochi.

320 Lo secundo sentimento si he:

Si e Audito. Se ay inteso voluntieri murmuratione et tardimenti. Se ay consentito a la morte et aylo inteso voluntieri. Se ay inteso voluntieri balare, o cantare, o soni vani.

78. Al igual que en Ex. 20,17 y en Dt. 5,21, la mujer es situada entre los bienes susceptibles de ser adquiridos o perdidos.

79. Palabra de difícil localización, probablemente "travenare": rezumar. El sentido, sin embargo, es claro: mercancías mojadas para que aumente el peso. 
Lo tercio sentimento si e Gusto.

325 Se ay magnato per delectacione et non per necesitate. Se ay magnato piu per amore de diversi cibi et sapuri et non per fame che abbi. Se ay peccato nela delectatione dela lingua la dicendo multe parole occiose per far ridere.

Lo quarto sentimento si e: Odorato.

Se ai tenuto alcuno oddore, o vero l'ay portato per deletamento adosso.

330 Lo quinto sentimento si e: Tacto.

Se ay tocata alcuna persona desonestamente, o vero toy membri nele membra de l'altre persona, como e le pope dela dona, o vero rose, o altre cose. Se avisi, abraciato o basato alcuna persona desonestamente et con malicia ay peccato mortalmente./ [150v]

335 Sequitano li XII articuli dela fede sancta

El primo si he: Credo in dio patre omnipotente creatore del celo et dela terra. El secondo: Ihesu christo suo figlo unico signor nostro. El terço: Lo quale fu concepto de spiritu sancto, naque de maria virgine. El quarto, Passionato soto la signoria de pillato, crucifixo, morto et sepulto. El quinto,

340 Decese a lo inferno, el tertio di resucito da morte. Lo sexto: Sali in celo, et sede dala parte dextra de dio. Lo septimo: Credere che de venir a iudicar le vivi et li morti. Lo octavo: Credo nelo spiritu sancto. Lo IX': Credo nela santa ecclesia [a]postolica. Lo decimo: La communione de li sancti. La remession de li peccati. Lo XI': La resurrecion de li morti. Lo XII ${ }^{\circ}$ : Vita

345 eterna. Amen.

Sequitano li VII sacramenti

El primo si e el bautismo. Si per tua [o]casione e morta alcuna persona sensa bautismo. El secondo si e La crisma. El tercio si e El matrimonio. Se ay usato el matrimonio nel debito modo. Se te si astinuto de redere el debi-

350 to neli tempi prohibiti dala santa ecclesia. El quarto he la strema uncio. Si sey stato unto nel tempo dela morte. El quinto si e La confessione. Se te sey confesato a lo meno una volta al anno. El sexto si e Prendere el cuerpo de christo ad meno una volta al anno. El septimo si e l'ordine crelicale. Se ay observato l'ordine diligentemente. Ista sunt, videlicet, sacramenta ecclesie.

355 Bautisma. Crisma. Matrimonium. Strema uncio. Confessio. Corpus christi. Ordo clericalis.

Sequitano le VII opere dela misericordia.

Prima visitar lo, infirmo. Se sey stato negligente ad visitar le infirmi, confortarli et ayutarly. La secunda: Se sey stato negligente a dar a bevere lo asse-

360 tato. La tercia: A dar a magnar aqueli che ano fame. Se sey stato negligente che non ay cibato lo affamato. La quarta: Recevere el pelegrino. Se sey stato negligente ad recollere le pelegrini. La quinta: Vestir el nudo. Se sey stato negligente ad vestir ${ }^{80}$. La sexta: recollere li prosimi. Se sey stato negli-

80. La frase queda interrumpida en esta línea, ya que se continúa en la primera línea de la página siguiente: “...negligente ad vestir el nudo povero...”. Pero el amanuense ha tenido 
gente ad recollere le prosimi/ [151r] el nudo povero. La septima: Sepelir li 365 morti.

Sequitano le VII opere dela misericordia spirituali.

La prima si e: consigliar lo ignorante. Se sey stato negligente a dar bon consiglio a li ignoranti daquello che dubitano. La secunda: Si e corrigere et castigare li viciosi, havendone autorita. La tercia: si e remetere l'ofese. Se sey

370 stato negligente a perdonar. Et remetere l'ofese ad qui ta iniurato. La quarta si e: substiner le iniurie. Se sey stato impatiente a sustiner le iniurie fati dali paççi et dali stulti. La V $\mathrm{V}^{\mathrm{a}}$ si e: pregar per li pecaturi. Se sey stato negligente ad pregar dio per tutti le peccaturi et per la ecclesia. La sexta: Elimo$\operatorname{sina}^{81}$, si e pregar per li morti. Se sey stato negligente a pregar dio per li

375 morti. La septima si e de consolar li afliti. Se non ay consulato lu afflito in la so adversita.

Sequitano le virtute theol[og]iche

Cio e, fede, speranza et carita. Se ay avuta vera fede in dio, o sperança. Se te sey consillato a li demoni et incantatori con carathere et con lincanti. Se

380 ay fata alcuna incantatula in polla, o vero chrispalo ${ }^{82}$ o in altro modo, o canata $^{83}$ l'erba el di de santo johani bautista, o vero altri, ${ }^{84}$ di per fare fatura $^{85}$, ay peccato mortalmente. Se ay tenuto el diabo in chiuso et cum ipso te sey aconsillato per alcuno modo. Se ay adoparata l'arte dela negromancia. Se ay demandata alcuna gracia a la sole, o a la luna, o a le stelle. Se

385 ay piu sperança nele persona che in dio. Se te sey desperato dela misericordia de dio et per questo non ay fato piu bene. Se ay contraduto a la verita contra constientia. Se sey stato duro nela mente resistento a li boni spirationi. Se te sey desperato de may non mendar la vita tua. Se ay avuta poca carita a dio et a l'anima tua et a li proximo tuo.

390 Sequitano le doni de lu spiritu sancto/ [151v]

Se ay avuta poca sperança in dio. Se non sey stato piatoso et paxionivele enele infirmitade del proximo tuo. Se non sei stato forte nele tentatione. Se non ay dato bono exemplo et conseglo a lo tuo proximo nela adversitade.

que añadir al final de esta página una línea adicional a fin de corregir su error, pues omitía la sexta obra de misericordia, pasando de la quinta a la séptima.

81. La palabra "elimosina" rompe el ritmo que ha seguido hasta ahora para la presentación de las obras de misericordia. Por otra parte, al presentar ésta, habla de las oraciones por los difuntos, pero no habla de rezar y dar limosna por los muertos.

8.2 A pesar de que el sentido podría inducir a la lectura: "christalo", la grafía señala inequívocamente "chrispalo", concepto del que resulta difícil precisar si alude a un recipiente (como anteriormente con "polla") o a algún tipo determinado de encantamiento.

83. La grafía no deja lugar a dudas sobre la lectura "canata"; el concepto "Canata l'erba el di de santo johani bautista" alude a alguna práctica ritualizada llevada a cabo precisamente en tal día "mágico", el del solsticio de verano.

84. La coma está señalada en este lugar, aunque evidentemente se trata de un error, pues el sentido reclama que vaya unido: "o vero altri di, per fare...".

85. "Fatura", del latín "fatum"; fare fatura: hacer predicciones, adivinar el futuro. 
Nota bene chi se vole ben confesar deve dir le peccati con le circustantie

395 soy, cio e, con que hai commesso el peccato con parente, o in qual grado, o persona religiosa, o vero altra persona. Que peccati ai conmesso; dirai li lo senza malicia. In que loco ay conmesso, o in chesia, o in altro loco. Con que adiutorio, pero propia malicia, o per altra (o)casione. Quante volte ay fato lo peccato. Et con quante persona. In che modo l'ai comesso, o humana400 mente, o vero bestialmente. Quando l'ay comesso, nel di dela domenica, o vero in di de altre feste. Et se l'ay fato secretamente, o vero in presentia daltri.

deo gratias 